\title{
Understanding Ethics in Sustainability Transitions: Towards Social Learning for Sustainable Food Systems
}

by

Christian Anton Robertson

Thesis presented in partial fulfilment of the requirements for the degree of Master of Philosophy in Sustainable Development in the Faculty of Economic and Management Sciences at Stellenbosch University

Supervisors: Dr. Rika Preiser and Prof. Milla McLachlan 


\section{Declaration}

By submitting this thesis/dissertation electronically, I declare that the entirety of the work contained therein is my own, original work, that I am the sole author thereof (save to the extent explicitly otherwise stated), that reproduction and publication thereof by Stellenbosch University will not infringe any third party rights and that I have not previously in its entirety or in part submitted it for obtaining any qualification.

Date: March 2014

(

]

प 


\begin{abstract}
$\underline{\text { Abstract }}$
This thesis explores the importance of an appropriate understanding of ethics in sustainability transitions. Through a conceptual analysis, it finds that the dominant understanding of modernist ethics is unsuitable to the contexts of contingency in sustainability transitions, and that the participatory understanding of ethics as a complex system presents a far more adequate approach to the ethical complexity of socioecological systems. In particular, the strategy of 'practising provisionality' is suggested, which understands the process of ethical decision-making as a process of social learning. This argument is further supported by a critical reflection on the food system context.
\end{abstract}

The present dangers and future uncertainties of sustainability transitions are issues of incredible complexity. Socioecological interactions can have unpredictable impacts on our ability to the needs of both current and future generations, like realising a sustainable food system. Moreover, there are difficult decisions that we also to make in such dilemmas, like the extent of natural resource exploitation, where normativity plays a large role. This means that these complex issues are also ethical issues. The importance of understanding ethics in sustainability transitions is, therefore, of great importance, since we will want to believe we are making the 'right' choices in these changing contexts. However, the understanding of ethics that dominates traditional scientific thinking and academic inquiries represents a paradigm of thought that is insensitive to complexity of socioecological systems, and is therefore, inadequate in addressing the ethical complexity of sustainability transitions. In the context of food systems, this is demonstrated in the linear emphasis on food production that dominates the ethics of realising sustainable food systems.

This thesis argues that a more appropriate way of thinking about ethics in times of contingent contexts and socioecological change would have to account for complexity. In an acknowledgement of the complexity of ethics, it is argued that every decision has elements of moral consideration, and that there is also no way to know objectively whether the respective decision was morally 'right' or 'wrong'. Such an understanding of complex ethics would, therefore, emphasise the importance of recursively reasoning through every ethical decision to address any reductionisms of complexity; adopting an attitude of modesty and openness towards dialogue, and adopting a student mentality of social learning that would improve upon one's complex ethical reasoning. Subsequently, the paradigmatic shift of a complex approach to ethics is more adequate in understanding ethics in sustainability transitions. 


\section{Opsomming}

Hierdie tesis ondersoek die belangrikheid van 'n toepaslike begrip van etiek in volhoubaarheidsoorgange. Die bevinding van hierdie konseptuele analise is dat die oorheersende begrip van modernistiese etiek ongeskik is in die volhoubaarheidsoorgang konteks van gebeurlikheid en dat die deelnemende begrip van etiek as 'n komplekse sisteem 'n baie meer toepaslike benadering is tot die etiese kompleksiteit van sosioekologiese sisteme. Die strategie van 'praktiese voorlopigheid' word in die besonder voorgestel. Dit sien die proses van etiese besluitneming as 'n proses van sosiale leerwyse. Die argument word verder ondersteun deur die kritiese refleksie op die voedselsisteem konteks.

Die huidige gevare en toekomstige onsekerheid van volhoubaarheidsoorgange is geweldige ingewikkelde strydvrae. Sosioekologiese interaksies kan onvoorsiene impakte hê op ons vermoeëns om die behoeftes van beide huidige en toekomstige generasies aan te spreek, soos om volhoubare voedselsisteme te laat realiseer. Verder is daar moelike besluite wat geneem moet word tydens sulke dilemmas, soos die mate waartoe ons natuurlike bronne geeksploiteer word, waar normativiteit 'n groot rol speel. Dit beteken dat hierdie komplekse strydvrae ook etiese strydvrae is. Die belangrikheid van die begrip van etiek in volhoubare oorgange is derhalwe van groot belang, aangesien ons wil glo ons neem die regte besluite in hierdie veranderende kontekste. Die begrip van etiek wat die traditionele wetenskaplike denkwyse en akademiese navrae domineer, kom egter voor as 'n paradigmiese denkwyse wat onsensitief is ten opsigte van die kompleksitiet van die sosioekologiese sisteme, en dus tekortskiet in die hantering van die etiese kompleksitiet van volhoubare oorgange. In die voedselsisteem konteks word dit gedemonstreer in die liniêre klem wat op voedselproduksie geplaas word, wat die etiek van die realisasie van voedselsisteme domineer.

Hierdie tesis redeneer dat 'n meer paslike denkwyse omtrent etiek in tye van gebeurlike kontekste en sosioekologiese veranderinge sal moet rekenskap gee van kompleksitieit. In die erkenning van die kompleksiteit van etiek, word dit geredeneer dat elke besluit 'n element van morele oorweging het, en dat daar ook geen manier is om objektief te weet of die respektiewe besluit moreel 'korrek' of verkeerd' is nie. So 'n begrip van komplekse etiek sal, dus die belangrikheid van konstante redenering in elke etiese besluitneming beklemtoon, om enige reduksionisme van kompleksiteit aan te spreek. Dit geskied deurmiddel van 'n houding van beskeidenheid en oopheid tot dialoog, en die aanneming van 'n studente mentaliteit van sosiale leerwyse wat 'n komplekse etiese redenering kan verbeter. Gevolglik, is die 
paradigmatiese verskuiwing van 'n komplekse benadering tot etiek meer paslik in die begrip van etiek in volhoubaarheidsoorgange. 


\section{$\underline{\text { Acknowledgements }}$}

I would like thank the many people and organisations that have each played a significant role in contributing to the completion of this study:

- I am grateful to the National Research Foundation (NRF) for their financial assistance. This work is based upon research supported by the NRF. Any opinion, findings and conclusions or recommendations expressed in this material are those of the authors and therefore the NRF do not accept any liability in regard thereto.

- I am also thankful to Stellenbosch University's Food Security Initiative, which granted me the opportunity of working with the Social Learning for Sustainable Food Systems project - a collaborative effort that has reignited my academic faith, and reminded me of the purpose of academia.

- I would like to extend my thanks to my friends and family, who I have relied on for comfort and direction in both the highs and lows of this strange year, from young love and optimism, to heartbreak and death. I apologise for any mood-swings and meaningless tantrums, and even though you who may never get the chance to read this, I hope to reciprocate that friendship and support when called upon.

- I am indebted to my inspirational supervisors, Dr. Rika Preiser and Prof. Milla McLachlan, whose wisdom has at times left me speechless. I think of Rika and Milla as two leaders in my own university residence of academic thoughts: Rika, the onderprimarius, who leads 'binnelandse sake'; and Milla, the primarius, who leads 'buitelandse sake'. Rika, thank you for letting me talk, for letting me find my feet, for trusting me and encouraging my ambitions. But most of all, thank you for keeping calm and wiping away the worry when those ambitions crumbled. Quite simply, I would have given up a long time if it were not for you, so this thesis is dedicated to you. If only all students could be as blessed to have a supervisor like you. Milla, thank you for believing in me - a philosophy student - and entrusting me with the responsibility of contributing to a worthy initiative. Your openness and imagination has given me direction in life, and you are the single reason that my passion for academia is now more alive and energised than ever before. Without your recommendation for the NRF bursary, I would not be writing this today. Most of all, I want to thank you for reminding me that the only worthy thesis is a finished one. 
- Lastly, I am grateful to those who have questioned me, for reminding me that life is not easy and that only practice makes progress. I especially want to thank those who continue to ask, "So, what will you do with a Philosophy degree?" If I had not received that constant criticism, although unintentionally demeaning, I would not have put so much passion into every step I have taken along the way - just so that one day I can confidently answer, "I will help you to make the world a better place." 


\section{Table of Contents}

Chapter 1: Introduction 1

- 1.1: Opening Remarks 1

- 1.2: Understanding the Link between Ethics and Sustainability 2

○ 1.2.1: A Note on Complexity 3

○ 1.2.2: A Note on Systems Thinking 4

○ 1.2.3: A Note on Food Systems 5

○ 1.2.4: A Note on Social Learning 6

○ 1.2.5: A Note on Writing Style 7

- 1.3: Methodology 8

○ 1.3.1: Structure of Study 9

Part 1: The Machine Mind and an Engineered Ethics 13

Chapter 2: The Machine Mind - a Critical Reflection on Modernist Thinking 14

- 2.1: Chapter Overview 14

- 2.2 : Thinking like a Machine 14

○ 2.2.1: Making Machines out of Mountains 15

○ 2.2.2: Making Divisions out of Differences 18

○ 2.2.3: Taking the Mountain out of the Mountain Range 21

- 2.3: Thinking like a Machine in the Context of Food Systems 23

- 2.4: Chapter Summary 26

Chapter 3: An Engineered Ethics - a Critical Reflection on Modernist Ethics 28

- 3.1: Chapter Overview 28

- 3.2: Manufacturing Morality 28

$\circ \quad$ 3.2.1: An Engineering of Ethics 29

$\circ \quad$ 3.2.2: An Electioneering of Ethics $\quad 32$

○ 3.2.3: An Evasion of Ethics $\quad 34$

- 3.3: Manufacturing Morality in the Context of Food Systems 37

- $\quad$ 3.4: Chapter Summary 40 
Chapter 4: The Mountain Mind - Imagining Complex Thinking

- 4.1: Chapter Overview 42

- 4.2: Thinking like a Mountain

- 4.2.1: Towards a Renaissance in Reductionism and Onwards 44

○ 4.2.2: Towards Binding Binaries and Beyond 47

- 4.2.3: Towards the Mountain Mind in Modesty 49

- 4.3: Thinking like a Mountain in the Context of Food Systems 53

- 4.4: Chapter Summary 56

Chapter 5: An Emerging Ethics - Imagining Complex Ethics 57

- 5.1: Chapter Overview 57

- 5.2: Practising Provisionality 57

○ 5.2.1: Towards a Renaissance in Responsibility and Onwards 59

○.2.2: Towards Collaborative Conversations and to be Continued 61

5.2.3: Towards an Emerging Ethics in Earnest 64

- 5.3: Practising Provisionality in the Context of Food Systems 67

- 5.4: Chapter Summary 70

Chapter 6: Conclusion 72

- 6.1: Closing Remarks 72

○ 6.1.1: Thesis Review $\quad 73$

- 6.2: Limitations of the Research $\quad 75$

- $\quad$ 6.3: Recommendations for Further Research $\quad 76$ 


\section{Chapter 1: Introduction}

\section{1: Opening Remarks}

This thesis is the result of a wrestle with the issue of sustainability transitions, in particular with regard to sustainable food systems, and also with the issue of ethics.

My interest in ethics had begun some time ago, as I grew dissatisfied with what I saw as the 'moral deficit' of the West's consumerist lifestyle, and the seemingly complete disregard for the future of all life on Earth, for generations to come. Then, I had the privilege of working with the Stellenbosch University's Food Security Initiative, and their transdisciplinary Social Learning for Sustainable Food Systems project, with which I was given the opportunity of providing some philosophical insight into the question of ethics in food systems.

My initial hope, therefore, was to develop an ethical manifesto, which would guide the project's academic inquiries going forward. However, with every project meeting, and with every piece of literature I read, I realised to my own dismay, that I could not follow through with my promise. Both my understanding and the team's understanding of ethics were predominantly stuck in an unsuitable way of thinking about, not only ethics, but about how the world works, and our relation to it. As my reading ventured into complexity theory and a complex conceptualisation of ethics, I started to see the world through new eyes, and I could not dare leave the team behind. As a result, I made a long-term decision that will hopefully benefit the project and also every individual team member: I had to park my own academic ambitions, and provide an accessible thesis that would inform how to think about our academic inquiries in a way that accounts for complexity, and as such, how this influences our understanding of ethics.

The intention, of course, is that my dedication to the project and the 'movement' will carry on, academically. However, that is for the topic of another thesis. In this case, my research has been focused on the notion that, before anything else, it is first necessary to put the project team and myself on adequate footing. Subsequently, rather than focus on a specific food systems issue, or provide an isolated case study, my aim for this thesis was to provide a way of thinking about this context that demonstrates an alternative to the paradigm that dominates traditional scientific thinking and academic inquiry - one which accounts for complexity - and as such, offer a suitably complex way of thinking about ethics in sustainability transitions. 


\section{2: Understanding the Link between Ethics and Sustainability}

Today, we find ourselves in a time of sustainability transitions (Swilling \& Annecke, 2012), whereby we aim to prosper as a responsible species in acknowledgement of the finite nature of natural resources and the interconnected stresses on socioecological systems. The effects of these crises have never before been experienced at the current scale of impact, and cut across our man-made borders and barriers. Sustainability transitions, therefore, "emerge when the following conditions are in place: finance capital has been disciplined; the digitization of production and consumption is further extended under the leadership of productive capital; and the installation of the 'green-tech' revolution driven by finance capital is accelerated in response to deepening ecological crises" (Swilling, 2013:97).

More interestingly, is that an approach to sustainability transitions not only contemplates sustaining life on Earth, but also "a search for good life and justice and ... [so] its normative character is undeniable" (Kagan, 2010:1098). However, when there are impoverished families on the streets of wealthy cities, and continued destructive exploitation of natural resources, the morality that is guiding the times has to be put under scrutiny. As such, it is necessary that an academic understanding of ethics is philosophically investigated, with regard to its appropriateness in these unpredictable times.

In an acknowledgement of the importance of this research, this thesis will explore the understanding of ethics that dominates moral philosophy in modern Western culture, and given the unexplored territory of sustainability transitions and its normative expectations, discuss whether this understanding is suitable. However, it will be revealed that the paradigm of thought that rules over today's academic inquiries, including moral philosophy, subscribes "to the concepts of an out dated worldview, a perception of reality inadequate for dealing with our overpopulated, globally interconnected world" (Capra, 1996:4). This is particularly relevant in the context of food systems, where the problems of "pollution ... animal welfare, soil erosion, loss of genetic diversity, genetic modification ... and food safety are all swept under the carpet of profitable production" (Zimdahl, 2002:51).

Of course, this presents a crisis of significant proportions, since the pressure of addressing this problem is not only unimaginably demanding, but the failure to do so would also be unimaginably unfavourable. However, it also presents an opportunity, since these "assumptions that have gone unexamined for decades are now being called into question, creating an opportunity for fresh thinking and innovative action" (McLachlan \& Hamann, 
2011:429). In this light, this thesis will argue that the current conceptualisation of ethics is not necessarily a matter "of a lack of moral integrity on the part of modern thinkers, but of the limitations of modernist rationality" (Cilliers, 2004:20). Subsequently, this thesis will argue that we need to rethink ethics in a way that would conceptualise this reorientation appropriately to the context of global polycrises; like ecosystem degradation, global warming, the phenomenon of 'oil peak', inequality, mass urbanisation, an imbalance in material flows, and food insecurity (Swilling \& Annecke, 2012).

An appropriate understanding of ethics in sustainability transitions will have to develop from a critique of the underlying structures of thought that informs modern moral philosophy's conceptualisation of ethics. Indeed, as academia slowly comes to understand the gravity of our global crises and the seriousness of what is expected of us, the weight of any philosophical investigation can no longer be content in "explaining why something is the way it is, but it needs to address the question of how it got to be that way" (Heylighen et al., 2007:131). As such, this thesis is as much about understanding as it is about understanding ethics. Subsequently, from such a critique, a more respectable notion of ethics can begin to grow from more adequate patterns of thinking, which will satisfy our approach to the contingencies of sustainability transitions.

This thesis will argue that the alternative of complex thinking provides a suitable paradigm of thought in this context, and that the understanding of 'complex ethics' that evolves out of this thinking, is sufficiently appropriate in addressing the ethical issues of sustainability transitions, particularly in food systems. Indeed, the literature that informs this argument for a revolutionary change of thought (Cilliers, 1998; Cilliers, 2000a; Cilliers, 2000b; Cilliers, 2004; Morin, 1992; Morin, 2007; Woermann \& Cilliers, 2012; Woermann, 2013) reveals that ethics is inseparable to a way of thinking that will account for the scale of the global polycrises.

\subsection{1: A Note on Complexity}

One of the foremost characteristics of sustainability transitions is that we are dealing with a complex reality (Swilling \& Annecke, 2012). However, complexity is a term that, by its nature, defies the usual dictionary definition of a word, since it "is often loosely appropriated to describe things that lack simple explanations" (Woermann \& Cilliers, 2013:403). 
Although there is no standard 'theory of complexity' that offers a neatly packed definition of what the notion of complexity means, one can recognise certain phenomena as having certain characteristics by which they are recognisable as being complex (Cilliers, 1998). Moreover, only a system of dynamically inter-related components can be complex. The complexity is located in the nature of the organization between the different parts and is not a characteristic of the atomistic entities (Preiser, Cilliers \& Human 2013; Morin, 1992).

Nevertheless, just because it is a difficult concept to get our head around does not mean we must neglect its importance. On the contrary, it is something that we have to confront and grapple with, since an honest reflection on ethics in sustainability transitions - as is the intention of this thesis - reveals that it is, indeed, an extremely complex issue. Yet, the dominant way of thinking about the world and how we relate to it, has long excluded this reality from its academic inquiries, and from its theories that inform them; hence the situation that we find ourselves in today. Moreover, the 'paradigm of complexity' (Morin, 1992) introduces a relational way of thinking that is often used to critique traditional scientific theories.

This has led Cilliers (1998:127) to quite rightly say that "we need to come to grips with complexity in order to ensure our survival" - a statement that will resonate throughout this thesis. Therefore, in this study, I argue that a rigorous understanding of the key implications of the complexity thinking paradigm reveals that the underlying assumptions that inform our understanding of complex phenomena are deeply related to ethical issues. For the purpose of this study I draw on a very specific philosophical interpretation of complexity as informed by the work of Cilliers (1998, 2000a, 2000b) and Morin (1992, 2007).

\subsection{2: A Note on Systems Thinking}

It is important to note that the idea of sustainability transitions is "a young concept for an age of hypercomplexity, where challenges of increasingly globalizing economic exchanges as well as cultural exchanges are combining with the challenge of interconnected global and local ecological and social crises" (Kagan, 2010:1094). In order to discuss something that seemingly defies description, an appropriate approach would, of course, have to be sensitive to these exchanges.

Therefore, this thesis suggests that, to account for these complex interactions between social spheres, ecological spheres, and the many other exchanges that occur within and in-between 
these worlds, an open systems thinking approach would be necessary - a complex systems approach. Indeed, if our academic inquiries are to recognise the complexity of sustainability transitions, it is also necessary to account for the fact that, as "the different economic, social, technological and ecological systems that we are part of become ever more interdependent ... the result is an ever more complex 'system of systems' where a change in any component may affect virtually any other component, and that in a mostly unpredictable manner" (Heylighen et al., 2007:117).

As such, through this way of seeing the world, as complex systems, we are able to "identify problems and possibilities that are simultaneously multidimensional, dynamic and evolving" (Blewitt, 2008:41), and appropriately understand ethics in sustainability transitions.

\subsection{3: A Note on Food Systems}

The significance of sustainability transitions is an enormous thing to think about, and perhaps, the most important story that we will tell in our lifetimes. Furthermore, understanding ethics in this context in a way that accounts for complexity is something that requires time and space to reflect upon. As such, there is the risk that we can get lost in this story if it is overcomplicated.

For this reason, rather than the isolating character of a case study, it will be necessary that this thesis commits to a more tangible context, so that the argument of an appropriate understanding of ethics gains more traction. A case study will be more applicable hereafter, once the conceptual heaviness of complexity and its impact on our understanding on ethics has properly sunk into our ways of thinking in general.

Food insecurity is one of the hallmark issues of the sustainability transitions challenge, since it identifies the precious balance between the ecological world and the social world that is needed to navigate life on Earth through these difficult times. On one hand, it represents the troubles at the heart of human survival, since "food is essential for people to live sustainable and healthy lives" (von Braun, 2009:9). On the other hand, of the same body, it represents the hardships of Nature's survival, because of our species' dependency thereon to thrive; as we plough the land and drink up the dams. As such, when food is the issue, it is for many people "their most immediate and regular connection with the earth" (McLachlan \& Hamann, 2011:429). 
Moreover, the issue of food security is a complex one. This has been echoed by many authors (Battersby \& McLachlan, 2013; Drimie \& McLachlan, 2013; McLachlan \& Hamann, 2011; Scherr, 2000; Swilling \& Annecke, 2012; Thompson, 1998; Von Braun, 2009; Zimdahl, 2002). For this reason, "a systemic approach is required to address food insecurity" (Drimie \& McLachlan, 2013:217). In order to address food security, it is, therefore, necessary to address the food system. In other words, from this point of view, ensuring food security is about ensuring a sustainable food system.

As such, the context that will be used as a soundboard to reflect on understanding ethics in sustainability transitions will be the food system.

\subsection{4: A Note on Social Learning}

The journey of sustainability transitions is itself a learning journey. Therefore, in introducing a reorientation of ethics, founded on the critique of the dominant paradigm of thought, this thesis demonstrates "a wider and ongoing, creative and prospective human endeavour" (Hattingh, 1999:80), which serves to better understand our contexts and the complexity thereof.

The argument presented in this thesis should, therefore, not be taken for granted, but seen as part of a rich collection of ever-expanding academic thinking. As such, it welcomes critical and constructive reflection, from which present and future disciplines can continue their respective investigations in the context of sustainability transitions.

Indeed, this emphasis on learning ripples throughout the literature that addresses sustainability and the need for a change in the way we think (Capra, 2002; Cilliers, 2006; Henry, 2009; Morin \& Kern, 1999). This is most notable with the concept of 'social learning', which itself is a term whose understanding is still developing (Cundill \& Rodela, 2012; Reed et al., 2010). Conveniently, the food systems context explicitly highlights the need to establish "effective approaches to research-policy linkages and social learning" (Drimie \& McLachlan, 2013:217).

However, this thesis will not go into depths concerning these developing definitions, as this will stray from the learning process of this thesis' argument itself; of understanding ethics in sustainability transitions. As such, the emphasis will rather be directed at establishing appropriate grounds of academic thought from which this process of learning can grow. 


\subsection{5: A Note on Writing Style}

In terms of style, along with regular academic writing, this thesis has employed the use of imagery - most notably metaphors and similes - when referring to the various scientific positions and paradigms. This has been done to complement the sticky subject matter with which one is posed when dealing with complex subject matter.

Due to the nature of this idea of complexity - that it eludes concrete description and prescription - the use of imagery allows one to think creatively about the subject matter of different paradigms of thought, and how to critique these positions. This style, which mixes creative writing with academic writing, is not only necessary, but it is also not new. Indeed, this is all part of the process, since "in revolutionary times like these ... new ethical metaphors are coined, new principles are put on the table, and unexpected conclusions are reached" (Hattingh, 1999:80). For instance, the modernist paradigm of thought has been compared to a 'machine mind', modernist ethics has been compared to an 'engineered ethics', the complex paradigm of thought has been compared to the 'mountain mind', complex ethics has been compared to an 'emerging ethics', and complexity itself has been referred to as 'beautifully messy'. Furthermore, the use of imagery pays tribute to the dynamic and ever-changing notion of complexity, by refusing to reduce complex subject matter to concrete descriptions. Therefore, this represents a necessary way in which to write about the term, and as such, represents a complex style of academic writing.

The use of narrative is also important in such circumstances. Although the choice was taken to stray away from using story-telling, this thesis does take advantage of the comforting use of the word 'we', which helps to reinforce the notion that one is always in exploration when investigating complex subject matter. In this light, Warren (1998:262) notes that this "gives voice to a felt sensitivity often lacking in traditional analytical ethical discourse ... [and] provides a stance from which ethical discourse can be held accountable to the historical, material, and social realities in which moral subjects find themselves".

Nevertheless, this is still presented in an academic environment, and subsequently, this creative approach will always be sure to support and source its imagination with reliable citations. 


\section{3: Methodology}

The methodology of this thesis aims to reflect on the perspectives provided regarding the question about whether our current conceptualisation of ethics is sufficient in addressing the sensitive and sticky realities of sustainability transitions. This thesis, therefore, takes the form of a conceptual analysis - a critical exploration of philosophical theory that reflects on the realities of the kinds of thought strategies that might be better equipped in dealing with sustainability transitions.

To begin with, a variety of literature was read and further researched that reflected upon the paradigm of thought that has dominated the modern, Western world, and its influence in addressing the complex nature of reality, as well as the uncertainty of sustainability transitions. From that study, the focus was concentrated on how this 'machine mind' way of thinking dealt with notion of ethics, and how it fares in addressing the contingency of moral dilemmas and the extended ethical issues of sustainability transitions. In response to the disappointing 'engineering ethics' that is offered by such a 'machine mind' paradigm, and which dominates our academic inquiries, the literature review continued, so as to look for a more appropriate understanding of ethics in sustainability transitions would look like.

As the research delved into complexity theory and systems thinking, its acceptance of contingencies and its relevance with regard to reflecting upon the socioecological balance posed a more appropriate way of thinking to address sustainability transitions. Thereafter, the investigation of this alternative 'mountain mind' way of thinking deepens into exploring how the notion of ethics is approached from this perspective. Subsequently, it is suggested that a 'mountain mind' understanding of this allows for an 'emerging ethics', which is cognisant of the acknowledgement of complexity. The study then proceeds by suggesting that such a new understanding of ethics is an appropriate way of addressing the contingency of moral dilemmas and the extended ethical issues of sustainability transitions.

Thereafter, research continued into literature that dealt with the context of food systems, so as to understand the intricacy of this context, and the sustainability challenges it faces. Then, through a critical reflection, an approach to this context was engaged with from each paradigm of thought and its understanding of ethics, in demonstrating the inappropriateness of the 'machine mind' and its 'engineering ethics', and the appropriateness of the 'mountain 'mind' and its 'emerging ethics'. 
The initial intention was to support this with field research, like interviews, observation, and the critiques of institutional and other formal documents. However, the literature regarding this subject matter is so dense and difficult to contextualise, that it has been necessary to commit the full time and opportunity of writing this thesis to a dedicated unpacking of this philosophical theory. As such, the argument of this thesis will only be informed by qualitative material, so as to secure a critical understanding of ethics in sustainability transitions.

\subsection{1: Structure of Study}

This study is divided into two parts. Part 1 is comprised of Chapter Two and Chapter Three, and offers a critical reflection on the dominant (or modernist) paradigm of thought and its understanding of ethics, namely the 'machine mind' and an 'engineered ethics', respectively. Part 2 is a response to Part 1. Mirroring the structure of Part 1, Part 2 is comprised of Chapter Four and Chapter Five, and presents an alternative paradigm to the modernist strategies by engaging with the implications of a paradigm of thinking that acknowledges complexity and its understanding of ethics, namely the 'mountain mind' and an 'emerging ethics'.

\section{Chapter Two:}

Part 1 starts with Chapter Two, which aims to offer a philosophical critique of the modernist paradigm of thought that informs current scientific thinking and academic inquiries, namely the 'machine mind'. It consists of five sections and sub-sections that, together, provide a structured and comprehensive critical reflection of the modernist paradigm of thought. This will all be reflected upon in context of academic interest in sustainability transitions.

The chapter begins by introducing the imagery that represents the way of thinking that dominates Western academia, namely 'thinking like a machine'. From this introduction, the next three sub-sections shed light on the fundamental principles of this way of thinking, as well as the implications thereof.

The first sub-section investigates the foundational structure and rationale of this way of thinking, through the imagery of 'making machines out of mountains'. The second subsection explores how this way of thinking addresses the contingency of difference, through the imagery of 'making divisions out of differences'. The chapter continues with its third subsection, through the imagery of 'taking the mountain out of the mountain range', complementing the previous two sub-sections with a critique on the specific implication of its disregard for the complex nature and importance of context. 
The chapter ends by reflecting on the influence of this paradigm of thought in the food systems context, and based on the critique provided, exposes how this way of thinking complicates the possibility of realising sustainable food systems.

Chapter Three:

This chapter uses the previous chapter's critique as a springboard, so as to identify how modern moral philosophy thinks about ethics, and why this 'engineered ethics' is inappropriate. Similarly, it consists of five sections and sub-sections that, in its critique, lay bare the failings of the modernist understanding of ethics. Again, this is reflected upon in context of a theoretical interest in sustainability transitions.

In reference to the previous chapter, this chapter also begins by introducing the imagery that represents the modernist understanding of ethics, namely 'manufacturing morality'. Following this introduction, the next three sub-sections unpack the fundamentals of modernist ethics, as well as the implications thereof.

The first sub-section investigates the motivation and method of dealing with moral dilemmas, through the imagery of 'an engineering ethics'. The second sub-section explores how modernist ethics confronts the contingency of difference in an ethical context, through the imagery of 'an electioneering ethics'. The final sub-section, through the imagery of 'an evasion of ethics', supports the critique of the previous two sub-sections with a follow-up critique on the implication of its corrupt notion of moral responsibility.

The chapter concludes by reflecting on modernist ethics' influence in the context of food systems, and based on the critique provided, concentrates on how this understanding affects the ethical approach of academia's involvement in food systems, and the implications thereof in realising sustainable food systems.

Chapter Four:

Part 2 opens with Chapter Four, which aims to imagine an alternative paradigm of thought that will more appropriately guide scientific thinking and academic inquiries in sustainability transitions, namely the 'mountain mind'. This chapter consists of five sections and subsections that, together, provide a systematic introduction to a complex way of thinking.

The chapter begins by introducing the imagery that represents a complex way of thinking, namely 'thinking like a mountain'. From this introduction, the next three sub-sections shed 
light on the fundamental principles of this complex way of thinking, as well as the implications thereof.

The first sub-section introduces the revolutionary structure and rationale of this complex thought, through the imagery of 'a renaissance in reductionism and onwards'. The second sub-section explores how this way of thinking embraces the contingency of difference, through the imagery of 'binding binaries and beyond'. The last sub-section of the chapter presents the inherently ethical element of this paradigm, through the imagery of 'the mountain mind in modesty', complimenting the implications of the previous two sub-sections by commenting on the necessary attitude of modesty.

The chapter ends with a reflection of this paradigm of complex thought's approach to the food systems context, and based on the introduction provided, presents how this way of thinking opens up the possibility of potentially realising sustainable food systems in sustainability transitions.

\section{Chapter Five:}

This chapter follows on from the insight provided by the previous chapter, so as to offer an alternative way of thinking about ethics in sustainability transitions, namely an 'emerging ethics'. Similar to the previous chapter's structure, this chapter consists of five sections and sub-sections that demonstrate the appropriateness of understanding ethics from a perspective of complexity.

In reference to the previous chapter, this chapter also introduces the imagery that represents a complex understanding of ethics, namely 'practising provisionality'. Following this introduction, the next three sub-sections unpack the fundamentals of a complex ethics, as well as the implications thereof.

The first sub-section introduces the incentive and strategy of addressing ethical complexity, through the imagery of 'a renaissance in responsibility'. The second sub-section explores how a complex understanding of ethics revels in the contingency of difference in an ethical context, through the imagery of 'collaborative conversations and to be continued'. The final sub-section, through the imagery of 'an emerging ethics in earnest', supports the implications of the previous two sub-sections by commenting on how the continuous commitment of 'practising provisionality' should be regarded as a process of social learning. 
The chapter ends with a reflection on a complex understanding of ethics' approach to the food systems context, and based on the introduction provided, presents how this way of thinking about ethics would be appropriate in addressing the ethical complexity of realising sustainable food systems in sustainability transitions. 
Part 1: The Machine Mind and an Engineered Ethics 


\section{Chapter 2: The Machine Mind - a Critical Reflection on Modernist Thinking}

\section{1: Chapter Overview}

In short, this chapter presents a critique on the paradigm of thought that dominates current scientific thinking and academic inquiries. As a conceptual analysis of the underlying structure of this way of thinking, this chapter will demonstrate the inadequacy of this paradigm of thought and its avoidance of complexity, and in doing so, argues that an appropriate way of thinking about sustainability transitions would have to deal with the importance of acknowledging complexity.

The first section will briefly introduce the imagery that represents this way of thinking's disregard of complexity, namely 'thinking like a machine'. Afterwards, the next three subsections will elaborate on its fundamentals and the implications thereof.

Firstly, through the imagery of 'making machines out of mountains', the ontological and epistemological structure of this way of thinking will be introduced, which will identify this paradigm's ignorance with regard to acknowledging complexity. Secondly, through the imagery of 'making divisions out of differences', is the exploration of how this way of thinking deals with the contingency of difference, and interacts with other ways of thinking. Thirdly, through the imagery of 'taking the mountain out of the mountain range', this subsection complements the previous two sub-sections with a critique on the implications thereof, focusing mainly on this paradigm of thought's disregard for the complex nature of context.

The final section of this chapter is a contextualised reflection of this paradigm of thought, with regard to food systems, and focuses on this way of thinking's effect on academia's interest in realising sustainable food systems.

\section{2: Thinking like a Machine}

The modern age has largely been dominated by a certain way of thinking about the world and framed how we study our relation to the world. From René Descartes to Isaac Newton, and subsequently throughout the history of traditional scientific paradigms, modernist rationality has long been regarded "as the foundation for science as a whole" (Heylighen et al., 2007:118). Given the strictly mechanistic character in its ontological and epistemological manifestations, this rationality can be called 'thinking like a machine'. 
The imagery of 'thinking like a machine' is a common representation of a way of thinking that disregards the complex nature of phenomena and the complex contexts in which we study this subject matter (Morgan, 2006). This is evident in modernist rationality's belief that the world is a simple object that can be easily studied by reducing it to simple and isolated parts, like studying the parts of a machine. Following this logic and applying it to the notion of rationality implies that our system of thought also works similar to an uncomplicated machine, through the inputs of sense perception and the outputs of knowledge claims. Subsequently, this supports the mechanical lens of linear observation from which this paradigm of thought studies the world. However, the world is complex - it is beautifully messy. It is what Swimme and Berry (1992:243) refer to as "a communion of subjects rather than a collection of objects. Undisputedly, our survival depends on creatively understanding this beauty - a space that has long been dismissed and excluded by the mechanistic position of the modern age. In this light, this way of thinking is inappropriate in dealing with the complex issues of sustainability transitions, like food security.

There is, therefore, an immediate need to rethink this thinking that dominates traditional academic inquiries, and to accept and integrate this complexity into these research studies. Of course, this stands in contrast to the confidence of scientific thinking that has influenced the Western world, and in many cases through constructive influence. However, this is no cause for alarm, unless we choose to remain 'thinking like a machine'.

\subsection{1: Making Machines out of Mountains}

Unpacking this paradigm of thought is not complicated, although "its implications are subtle" (Heylighen et al., 2007:118). Therefore, it will be necessary to reflect on this thinking, so as to understand its benefits and its limits in a suitable approach to the world. Indeed, it is through reflecting on these foundational implications that an informed critique on the inappropriateness for our modernist understanding of ethics can be built, which will be elaborated on in the next chapter.

The rationality that has characterised our modern age "emerged out of the discovery that human order is vulnerable, contingent and devoid of reliable foundations" (Bauman, 1992:xi). However, instead of accepting its humbling experience, this discovery was immediately countered with a desperate attempt to control the contingency and 'restore order'. Firstly, it is important to acknowledge that, whilst human order is, indeed, susceptible to the contingencies of nature, the 'outside' world is, of course, also vulnerable to its own 
effects. There is a relentless display of death and destruction, unlike the romantic idealism of the world as a well-oiled machine. As such, "there is no such thing as 'nature's balance', no real or primordial nature that would be in equilibrium if only humans had not intruded" (Urry, 2005:6). It is, therefore, a fallacy to believe that we can somehow 'restore order'. Nevertheless, this does already provide some insight into the attitude of modernist thinking.

In order to address the vulnerability of our position, modernist thinkers have employed a method of simplification known as 'reductionism', in which it is desperately sought "to gain complete understanding and mastery of a phenomenon by breaking it down into its component parts" (Harding, 2006:31). Its influence has been so extensive that it has been championed for centuries, and has shaped a mechanistic "perception of nature, of the human organism, [and] of society" (Capra, 2002:102). Modernist thinking's strict dependency on reductionism depends on three basic principles of "determinism, materialism and objective knowledge" (Heylighen et al., 2007:120). Indeed, by isolating our studies to a phenomenon's parts, and the parts of those parts, one is forced to employ a way of thinking that "reduces all phenomena to movements of independent, material particles governed by deterministic laws ... [and] holds the promise of complete, objective and certain knowledge of past and future" (Heylighen et al., 2007:131). The system is reduced to its parts, like reducing a mountain to a machine.

Of course, it is not necessarily reductionism that is at fault, but the modernist way of thinking that has a complete reliance and belief that these principles are sufficient in providing objective knowledge about the world - a strict reductionism. Admittedly, there may be groups of phenomena that are just large enough and just small enough to satisfy this reliance, but "between these two extremes, however, lies a third group of phenomena that are too diverse for analysis and too structured to be random" (Clayton \& Radcliffe, 1996:16). In this case, this rationality is ineffective and often harmful. As such, this thesis argues that, from this paradigm, reductionism is both the method and the goal. The ontological questions and the epistemological questions of 'thinking like a machine' are reliant on each other; even though this is in contradiction to the traditional understanding that questions of what exists and questions of how do we know what exists are separated fields of philosophy (Heylighen et al., 2007). In other words, a modernist approach can only overcome contingency through order if it is working with things that are controllable. And so, as academia is guided by the desire to control everything around us, it continues along a linear "obsession to find one essential truth" (Cilliers, 1998:112). 
This motivation of rampant reductionism is theoretically supported by the modernist idea that "human agency is founded upon the idea of an a priori core self, capable of undertaking rational and causal actions, and thereby of being in control of itself and of the environment" (Woermann, 2013:9). So, not only are we competent enough to access apparently absolute truths that are somehow 'out there' waiting to be uncovered, but because of this distancing, we also have no need to include ourselves, as components, in the equations of our studies. As such, from the perspective of modernist academia, it is presumed that research strategies "are value-free and fixed entities, leaving the subject-object divide uncontested" (Audouin et al., 2013). In this light, the separations of philosophical questions exist not only in ontology and epistemology, but also with regard to ethics, since it is these marginalised questions of philosophical meaning and values that are "usually considered to be outside the scope of science" (Heylighen et al., 2007:117). And so, its rule over science has been unchecked and unaware of its "potentialities of destruction and of manipulation" (Morin, 2007:21).

The commanding position of superiority that reductionism enjoys already raises very poignant questions about the exclusive applicability of such a paradigm, especially of one that is centuries old. This thesis argues that 'thinking like a machine' has had its chapters in the story of human inquiries, and that, perhaps, it is high time that academia begins to reformulate its endeavours on foundations that are more suitable to our current context. Nevertheless, the strictly reductionist mindset still sees simple, separated components in contexts, and so, we continue "a monologue ... based on epistemologies of domination and control” (Blewitt, 2008:37) - we continue 'thinking like a machine' - and as a result, we fail to understand the intricate nature of our socioecological systems and the problems with which they are now defined. This spells disaster for our sustainability efforts and sustainability transitions as a whole, since "an isolated, stand-alone issue is likely to result in ... unintended consequences and inefficiency" (Drimie \& McLachlan, 2013:218). Indeed, to echo the introduction, as "the different economic, social, technological and ecological systems that we are part of become ever more interdependent ... the result is an ever more complex 'system of systems' where a change in any component may affect virtually any other component, and that in a mostly unpredictable manner" (Heylighen et al., 2007:117).

The very real dangers and stresses of the many global polycrises that threaten life on Earth, therefore, challenge academia to seriously reflect on its role in this situation. However, because of the continued dominance of this 'machine mind' paradigm, there has been insufficient attention paid to the possibility that the very way we think about the world could 
be at the root of many of these crises. Indeed, even though "our way of doing science in the West has inadvertently contributed to the many problems we face" (Harding, 2006:15), much of Western academia continue with this way of thinking that detrimentally disregards the nature of socioecological systems. As such, it is imperative to acknowledge that this way of thinking still stubbornly lingers, and that the centuries-old war on Nature continues, perceiving her as "no more than a dead machine to be exploited as we wish for our own benefit, without let or hindrance" (Harding, 2006:19).

This is not to say that the philosophical principles that define the modern age have no place in solving our global issues - far from it. The point is, rather, that the fixated and frigid structures of the current paradigm of thought do not give adequate recognition to the importance of contingent contexts in approaching complex systems, and thus do not allow for the appropriate usage of these philosophical tools. Ultimately, there will be certain aspects of this way of thinking that will remain useful to academia, but for now "we need to be prepared to question every single aspect of the old paradigm" (Capra, 1996:8). So, as the complex nature of our problems slowly come to light, this thesis argues that, at the same time, it is necessary to also question the dominance of this mechanistic perspective, which has neglected to acknowledge this very complexity.

From this self-assuring position of supposed objectivity, scientific thinking is supposedly supplied with the control to 'restore order', and as such, continues to dangerously deny that we are dealing with complexity. This desire continues to captivate the minds of our current leaders, entrenching a certain way of thinking about the world and how we relate to it. Whether it be desperation or a dream of order, this stubbornness has resulted in "nothing less than our imprisonment" (Cilliers, 1998:138), and only by understanding what it means to be 'in jail' can academic inquiries begin to reflect on the responsibility of acknowledging complexity.

\subsection{2: Making Divisions out of Differences}

Strictly reductionist strategies of inquiry cannot avoid the contingencies it desperately tries to deny. Subsequently, the beautifully messy nature of complex phenomena are in direct confrontation with the modern dream of order, which does not allow any irregularities or imperfections "to exist, let alone claim legitimacy" (Bauman, 1992:xii). To manage the messiness of complexity, the 'machine mind' employs what this study will refer to as a 'conservative' binary logic that is geared to sort out the contingency and irreducibility of 
complexity. This binary logic is a continuation with compartmentalisation that has become foundational to 'thinking like a machine'.

To ensure order, a conservative binary logic entails formalising some things that 'fall outside the bracket', but also denying that which emerges from the "grey area of ambivalence, indeterminacy and undecidability" (Bauman, 1992:xvi). This hierarchical way in which the mess is managed is evident in the pervasive dualistic ordering "of subject/object, $\mathrm{mind} / \mathrm{matter}$, nature/society, and so on - that dominates modern thinking" (Mebratu, 1998:512). Thinking in terms of hierarchy is itself not the problem, per se, but rather how this hierarchy is manipulated -as divisions rather than differences. Cilliers (2001:144) says that whilst the hierarchical ordering of differences is necessary to create meaning, "as the context changes, so must the hierarchies". For example, hierarchical thinking is necessary "for classifying data, comparing information, and organizing material" (Warren, 1998:258), but when one thing is subjected to an oppressive and unchanging relationship, it is detrimental to both the thing and the system in which it exists.

According to the work of Derrida (1981:41), this is what we are dealing with in traditional philosophy, whereby "we have not a peaceful coexistence of facing terms but a violent hierarchy ... [where] one of the terms dominates the other". As Ernst Friedrich Schumacher (1973:13-14) is remembered for saying, "modern man talks of the battle with nature, forgetting that if he ever won the battle he would find himself on the losing side". However, this so-called 'battleground' of Earth is a shared space, and there cannot be a commitment to such a battle. So, where reductionism's formalisation is somewhat generous, there still remains a problematic desire to order differences in boxes and then set them up against each other. And so, whether formalised or denied, these things are both subjected to a hierarchy of domination. This logic should, therefore, be interpreted as exclusionary, not inclusionary, as it is an acknowledgement of divisions, not of differences.

It is an unreflective alignment to strict reductionism, of believing objective knowledge to be at the end of an equation of components, which makes our minds "harden into inflexible and polarized oppositions" (Mebratu, 1998:512). These theoretical dichotomies are clearly present in academia - a place where human survival invests much of its hope, with regard to guiding us through sustainability transitions. Our modern knowledge is commonly set up against these kinds of opposing backdrops: science versus religion; West versus East; topdown versus bottom-up; quality versus quantity; and even sustainability versus development. 
The strictly reductionist method of the 'machine mind' has, therefore, also reduced what can fundamentally be called knowledge; "it has become the bearer of death" (Morin \& Kern, 1999:128). However, these polarities are only a product of reduction, not of reality. Such a rationalisation overlooks the historic ties and interdependence of any academic issue, and makes competing armies out of its parts. Subsequently, this paradigm of thought not only fools itself into thinking that "can entirely contain all knowledge within its own fields" (Nicolescu, 2002:33), but it also encourages a behaviour of ruthless rivalry.

Instead of solving the world's problems, we are left with leading thinkers in competition, not in collaboration, and academic departmentalisation that "has been significant for the maintenance of disciplinary autonomies, for the competition of research funds, and for the consolidation of academic prestige" (Max-Neef, 2005:6). The conservative binary logic of strict reductionism, therefore, obligates scientists to pursue their goal within a specific scientific paradigm, and this "implies a willingness to try and extend the explanatory power of that paradigm" (Emmeche, 2004:21). Pertinent issues, as a result, are considered only as a stage to belittle opposing camps.

Obviously, at a time when ecological collapse is just around the corner, when economies are stuck in recessionary ruts, and when societies are in disunity and disarray, this is not an acceptable approach from academia. However, we need to understand that this "mutilated thinking and blind intelligence ... is not rational, but rationalizing” (Morin \& Kern, 1999:129). As elaborated on by Cilliers (2003:8), what is claimed to be objectively superior seems "less to do with rationality and more with power". Nevertheless, this thesis argues that, if we are able to acknowledge that our academic inquiries need to account for their enabling role in sustainability transitions, we can move forward to rethink the ways of thinking that dominate academic inquiry.

This presents one of the biggest challenges for scientific research in the context of sustainability transitions - how do we work together? Interdisciplinarity, as well as the movement towards transdisciplinarity, should help in understanding complex sustainability challenges more contextually, and allow for a more appropriate approach. Yet, as long as academia remains blissfully unaware in this paradigm of thought - and remains 'in jail' "the possibility of thinking and the right to think are denied by the very disciplinary organization of scientific knowledge" (Morin \& Kern, 1999:125). 


\subsection{3: Taking the Mountain out of the Mountain Range}

Of course, a myriad of medical discoveries and technological inventions can be traced back to principles of reductionism. However, it is difficult to disagree with the fact that "the amazement we feel in contemplating these wonders of industrial and informational technologies is tinged by a sense of uneasiness, if not outright discomfort" (Capra, 2002:98). This is because, on its own, a method "that is based on analysis, isolation and the gathering of complete information about a phenomenon" (Heylighen et al., 2007:117) is unable to acknowledge the complexities of socioecological dynamics.

Society runs like clockwork according to the assumptions of deterministic simplification. Under the lens of reductionism, even the hands of the clock are undisputedly accurate, because time - like all phenomena - is, apparently, something "infinitely divisible into spacelike units, measurable in length, expressible as a number and reversible" (Urry, 2005:4). Yet, a deeply honest investigation into what we hold dear reveals that, rather than isolated, "all of the properties that matter to us in everyday life, such as beauty, life, status, intelligence ... turn out to be emergent" (Heylighen et al., 2007:121). Once things are separated into components, however, this insightful understanding is dismissed, as is the importance of how their contexts create their meaning - changing contexts change hierarchies, and thus change meaning (Cilliers, 2001). After all, even "a minimum of knowledge about knowledge teaches us that the most important factor is contextualization" (Morin \& Kern, 1999:123). The problem, therefore, lies in the fact that 'thinking like a machine' can only be "applied with success to static systems with interchangeable parts" (Hattingh, 1999:72). Again, the ontological-epistemological link can be acknowledged, in that how the socioecological systems of our studies are approached determines that what is seen is devoid of contextual significance.

When scientific thinking engineers knowledge, there is no space for context in our equations. The one-dimensionality of this way of thinking has, therefore, "led us to underestimate or simply be blind to system effects even when they are upon us" (Blewitt, 2008:43). It is this insistence on converting research experience "into numbers or abstractions as quickly as possible ... [that] marginalises the phenomenon, and inhibits the possibility of the perception of depth and intrinsic value in the thing being studied" (Harding, 2006:31). And so, it is this blind faith in this way of thinking that has detrimentally excluded other avenues of understanding; "the fascination produced by reason has been so immense, that we have lost 
other faculties and sentiments that facilitated ... our understanding of Nature from within" (Max-Neef, 2005:10). Subsequently, this thesis stresses the importance of acknowledging that the foundations of much of Western academic knowledge are built on sand, not stone explanations that attribute all success to a method of strict reductionism will always be insufficient. Indeed, "innovators in all fields, whether in the sciences or not, often rely on intuition ... [but] when they share with, or exhibit their results to, colleagues, the tendency is to reduce their expressed findings to reductionist and rational approximations" (Max-Neef, 2005:10-11). This has unfortunately left academic inquiries with mentalities that are "the most urgent problems and the ones most difficult to resolve" (Morin \& Kern, 1999:128). Moreover, this has trickled over into the public sphere, as we "demand clear and direct answers, actions and solutions, but life, and science, is not like that" (Blewitt, 2008:43).

This avoidance of acknowledging context and its importance to knowledge formation is also an avoidance of subjectivity and its importance. As said by Morin (2007:21), academia has respectfully "developed extremely sophisticated means to know external objects, but no means to know themselves". As such, this study argues that this lacking understanding of context is, therefore, an empty understanding of ourselves, and this "is the price we pay for objective knowledge" (Nicolescu 2002:13). The result is that, in their research, scientists' "ethical, political and value judgements are plainly excluded or left along the road" (MaxNeef, 2005:8). However, it is not that those judgements are not there, it is simply that "the conceptual underpinning and empirical evidence base for perspectives and approaches ... are often more implicit than explicit” (Drimie \& McLachlan, 2013:218). This has allowed scientific thinking to extend the fallacy with which it has long fooled itself and the world that the facts at the end of our equations are value-free. In reality, however, these "facts emerge out of an entire constellation of human perception, values, and actions - in one word, out of a paradigm" (Capra, 1996:11). So long as those committed to sustainability transitions see themselves as epitomised by the 'centred self' - "the idea of an a priori core self ... [which] presumes that we are fully transparent to ourselves" (Woermann, 2013:9) - the successes of these inquiries will always be tainted by this exclusion of our subjective input.

In terms of addressing our global polycrises, these strictly reductionist tools of isolation "have long been used, with minimal success" (Gardner, 2003:175). Even more worrying is that they have, in some places, worsened the crises. Nevertheless, it has been proudly professed, in confidence or arrogance, that the method of strict reductionism will "sooner or later overcome all remaining obstacles" (Heylighen et al., 2007:121). Therefore, in ignorance, 
inquiries into sustainability transitions carry on with the same thinking that has largely been the cause of these predicaments, and expect new solutions; as if the owls of Minerva would be better off as aeroplanes. This dangerously deep-rooted oversimplification is what is referred to as "the rationalizing idea of guaranteed progress" (Morin \& Kern, 1999:129). However, like Werner Heisenberg (1958) has said already, "what we observe is not nature herself, but nature exposed to our method of questioning". Academic inquiries must, therefore, accept the realisation that when phenomena are studied out of their context, like studying a mountain in isolation from its mountain range context, only an inadequate understanding is achieved.

In its dream for order, 'thinking like a machine' has denied contradictions and absurdities. But, the irony is that this paradigm's overload of reductionism is what is truly contradictory and absurd. In the attempt to reduce objects into knowable parts, the defining context has been excluded, which renders a 'complete' understanding impossible. So, when this modernist paradigm of thought went "to fish for order in the sea of nature ... it caught no fish - only fishbones" (Morin, 1992:383). This thesis argues, therefore, that objectivity under the lens of strict reductionism is only an out-of-context and reduced objectivity.

\section{3: Thinking like a Machine in the Context of Food Systems}

Understanding the implications of our dominant paradigm of thought is critical to providing a more appropriate foundation from which complexity can be acknowledged in academic thinking. This is especially relevant when the global polycrises are considered, and that there is a need to guide inquiries through sustainability transitions. Therefore, to provide a deeper understanding of the 'machine mind', it will be helpful to contextualise 'thinking like a machine' in our commitment to realising sustainable food systems.

When we are 'thinking like a machine' in the context of food systems, it is believed that the employment of strict reductionism will grant us the objective knowledge that will ultimately be the key to 'feeding the world'. This linear thinking, which simply equates a sustainable food system to a system that increases food production, is what is called the "production paradigm' (Chrispeels \& Mandoli, 2003). Indeed, modernist approaches to food system issues "find expression in strategies of analysis that isolate system components in the study process" (Audouin et al., 2013); compartmentalising agricultural land into managed blocks, so as to deterministically achieve food production - to engineer what we eat. 
There is no question that, in order to 'feed the world', food systems will have to efficiently produce crops to meet ever-growing demands. However, even though the emphasis has been on production, there has been "slow progress in reducing hunger in past decades ... [and] the number of undernourished people in developing countries actually increased from 823 million in 1990 to 923 million in 2007" (von Braun, 2009:9). This thesis argues that the reason for this can be ascribed to the one-dimensionality of the 'production paradigm', which neglects the contextual complexity of food production, with devastating trade-offs in food nutrition and the integrity of our natural resources. The aim of sustainable food systems is, of course, to interrogate and reconceptualise the food security challenge (Drimie \& McLachlan, 2013), but this challenge goes beyond quantity. Indeed, a sufficiency of food is one of the cornerstones of food security, but it must also represent a contextualised, equitable food system "where malnutrition is absent, and where food originates from efficient, effective, and low-cost food systems that are compatible with sustainable use of natural resources" (IFPRI, 1995:1).

However, in this modernist rationality's arrogant self-confidence, it is thoughtlessly advocated that an industrialised, chemical-intensive agriculture will suffice, which is only streamlined to maximise production. Ironically, this wrecks the fertility of the very resource food production depends on - soil. Scherr (2000:479) warns that this reckless disregard for context could lead to "a downward spiral", whereby those involved in the food system run the risk of further impoverishing and endangering the very communities they try and 'save' with their production methods. However, it would be as foolish to completely throw out the input of chemicals and pesticides, and so, a more frugal approach would be more conscious of the sensitivity of food systems context. As suggested by the International Food Policy Research Institute (1995:33), "past and current failures to replenish soils with the nutrients removed must be rectified through the balanced and efficient use of plant nutrients from both organic and inorganic sources".

Nevertheless, not only is there a strict obedience to the 'production paradigm', but when 'thinking like a machine', the academic influence in food systems has sought to ensure its position of objectivity by rejecting any contrasting claims. This has stagnated the necessary scientific progress that could emerge from academic dialogue, and has deepened "divisions amongst the 'producers' of scientific knowledge and between the 'users' of this and other forms of knowledge" (Burns, Audouin \& Weaver, 2006:379). Of course, we must be reminded that the oversimplificaion of exclusive, disciplinary approaches "makes rational 
discourse among stakeholders from different disciplines, sectors and levels difficult, and prevents them from working together effectively to find innovative ways to respond to food security challenges" (Drimie \& McLachlan, 2013:218). However, the complexity of food systems challenges are such that they "cannot be understood and addressed using monodisciplinary approaches only" (Drimie \& McLachlan, 2013:219), and as such, the hope of realising a sustainable food system is always threatened by this 'violent' academic hierarchy.

In recalling what was said by Cilliers (2003:8), this kind of setting for an academic knowledge has "less to do with rationality and more with power". This is evident in academia's efforts to 'feed the world', as witnessed in the shockingly widespread abuse of power displayed by editors of scientific journals; like that of the Food and Chemical Toxicology journal's Richard Goodman, a former Monsanto employee, whose recent "fasttracked appointment, directly onto the upper editorial board raises urgent questions" (Robinson \& Latham, 2013). This appointment occurred after a study (Séralini et al., 2012) linked Monsanto - a giant corporation in industrial agriculture - to dangerous health risks. The result of this was to regulate the debate and the information with articles that criticised and discounted the study against Monsanto. More worrying, however, is that many of these criticisms were made with implicit values not made explicit. For example, some of the strongest criticisms came from Paul Christou, who has vested interests in Monsanto's success - he is an inventor of some of their genetically-modified crop patents - and who published his responses in the Transgenic Research journal, of which he is editor-in-chief (Robinson \& Latham, 2013). This thesis emphasises, therefore, that any attempt to control academia and knowledge itself "is not merely a technical or descriptive error, it is unethical" (Cilliers, 2004:23).

In light of this reflection on how 'thinking like a machine' influences how the context of food systems and the issue of food security are understood, this study acknowledges the inappropriateness of the 'machine mind' paradigm in realising sustainable food systems. The employment of strict reductionism has meant that the complexity of food system challenges is disregarded, and as such, that only fast-tracked food production is underscored, which this study believes is insufficient. This avoidance of acknowledging the complex context of sustainability transitions will mean that the modernist mission to 'feed the world' will not only fail, but in its failings will also risk the stability and integrity of ecological systems. Furthermore, a conservative binary logic, which seeks to ensure 'order' from a position of objectivity, has meant that any debate has been met with hostility, and as such, there is 
clearly "no room for flexible adaptations, learning, and evolution in the machine metaphor" (Capra, 2002:105). Indeed, this modernist rationality's possibilities for social learning to take place are too limited to satisfy our necessary scientific will, as these "narrowly disciplinary or academic modes of research or learning - and attempts to integrate such learning - cannot deal adequately with the challenges of food insecurity" (Drimie \& McLachlan, 2013:219). This is shameful, since we are in a time of transition that we have never experienced before, and there exists no scientific high-ground to guide us successfully towards sustainable food systems.

Whilst the 'machine mind' can be argued to be implicitly unethical, it is still important to ask how this paradigm of thought explicitly answers the philosophical questions of what it means to be ethical. This will not only provide this thesis with more insight into the 'machine mind', but it will also provide a platform from which a more appropriate understanding of ethics in food systems can be argued. As such, it is, therefore, necessary to investigate how 'thinking like a machine' influences a philosophical understanding of ethics.

\section{4: Chapter Summary}

This chapter has presented a critique on the paradigm of thought that dominates traditional scientific thinking and academic inquiries. As a conceptual analysis of the underlying structure of this way of thinking, this chapter has provided the necessary space from which its understanding of ethics can be investigated.

The first section introduced the imagery that represents this way of thinking's disregard for complexity, namely 'thinking like a machine'. Afterwards, three sub-sections were introduced, which elaborate on its fundamentals and the implications thereof.

Firstly, through the imagery of 'making machines out of mountains', the ontological and epistemological structure of this way of thinking was introduced, which identified this paradigm's ignorance with regard to acknowledging complexity. Secondly, through the imagery of 'making divisions out of differences', it was explored how this way of thinking deals with the contingency of difference, and the interaction with other ways of thinking. Thirdly, through the imagery of 'taking the mountain out of the mountain range', the next sub-section complemented the previous two sub-sections with a critique on the implications thereof, focusing mainly on this paradigm of thought's disregard for the complex nature of context. 
The final section of this chapter provided a contextualised reflection on this paradigm of thought, with regard to food systems, and focused on its effect on academia's interest in realising sustainable food systems. 


\section{Chapter 3: An Engineered Ethics - a Critical Reflection on Modernist Ethics}

\section{1: Chapter Overview}

In short, this chapter elaborates on the previous chapter's critique, by investigating how the 'machine mind' way of thinking approaches the question of ethics, and how this manifestation is inappropriate in the context of sustainability transitions. As a continuance of the conceptual analysis, this chapter will provide the necessary base from where a more appropriate way of thinking can be introduced that is more fitting in the context of sustainability transitions - from the lens of complexity. Thereafter, an alternative and contextualised understanding of ethics will be proposed.

The first section will similarly present the imagery that demonstrates how this understanding of ethics disregards complexity, namely 'manufacturing morality'. Following this introduction, the next three sub-sections unpack the fundamentals and implications of such a modernist understanding of ethics.

Firstly, the metaphor of 'an engineering ethics' presents the motivation and method of dealing with moral dilemmas, elucidated in a continuation of ignorance towards complexity. Secondly, the metaphor of 'an electioneering ethics' is used to investigate how modernist ethics confronts the contingency of difference in an ethical context. Thirdly, through the imagery of 'an evasion of ethics', this sub-section supports the critique of the previous two sub-sections with a follow-up critique on the implications thereof, focusing on how modernist ethics offers an inadequate understanding of moral responsibility.

The last section of this chapter is a contextual reflection on the modernist understanding of ethics with regard to food systems, and concentrates on how this understanding affects academic interest in realising sustainable food systems.

\section{2: Manufacturing Morality}

'Thinking like machine' has significantly shaped how we approach the world, making no exception of how ethics is understood. This way of thinking has mechanically instructed how we relate to the world, prescribing the understanding of ethics as a metaphysical engine of 'right and wrong'. However, ethics is not an engine whose parts can be studies and applied objectively. There are no blueprints to ensure accurate ethical behaviour. The modern dream of order, therefore, remains just that: a dream. 
Through an approach of strict reductionism, which assumes that "all phenomena, whether physical, biological, mental or social, are ultimately constituted of matter" (Heylighen et al., 2007:118), the dominant paradigm of thought aims at 'manufacturing morality'; looking to regulate social behaviour by means of moral rules. However, to try and control societal interactions is to try and do away with the ever-contingent dilemma of understanding what is 'right' and what is 'wrong'. This attempt to overcome the contingency is, therefore, only successful in being "a noble ideal" (Cilliers, 1998:137). By 'manufacturing morality', the richness and importance of ethics is reduced, and therefore, its approach to moral dilemmas is like that of an engineer to an automobile. Yet, its service is more like that of an engineer to an artwork, which only complicates something already so complex. As such, a modernist understanding of ethics will only continue to misuse and misunderstand something that says so much about what it means to be alive today.

Having unpacked the underlying structures of the 'machine mind' paradigm of thought in Chapter Two, this chapter will examine its influence and modernist grip on moral philosophy. A 'machine mind' will always supply an 'engineered ethics', and 'thinking like a machine' will always result in 'manufacturing morality'. The strictly reductionist leanings that are employed in modern moral philosophy will, therefore, be demonstrated to be inadequate in understanding the complex nature of ethics in sustainability transitions. So, as we begin to rethink our paradigm of thought, we must also begin to rethink our engagement and decisionmaking with regard to moral dilemmas.

\subsection{1: An Engineering of Ethics}

As a philosophical reflection on how we socially interact and express ourselves, ethics has been a contested topic for hundreds of years. As Socrates is remembered for noting, it concerns "no small matter, but how we ought to live" (Rachels \& Rachels, 2007:1). Its significance, however, can only be understood when it is realised that it is the moral choices that determine the difference between 'how we live' and 'how we ought to live'. Yet, the dream of order has denied us the freedom of decision-making, with the aim of "controlling individual and interpersonal behaviour" (Clayton \& Radcliffe, 1996:2-3).

The belief of modernist ethics is that there are apparently a priori moral facts that exist and are discoverable from the supposed position of objectivity. Such an understanding assumes that moral dilemmas can be ordered and judged from an objective and neutral position. And so, in an attempt to crush the contingencies of moral dilemmas, modernist ethics aims to 
satisfy these moral conundrums by arguing "for universal ethical principles, principles that would always apply to everybody" (Cilliers, 2004:20). The linear rationalising is that if these moral rules are followed, justice will be served, and by ensuring justice, so too is order ensured. It is the obedience to these moral rules, therefore, that allows modernist ethical theories to do away with the difficult decisions of a moral dilemma, thereby “decomplexifying it" (Morin, 2007:10). This is modernist ethic's simplistic way of differentiating between the 'good' and 'bad, and the 'right' and 'wrong' in the onedimensional journey of 'how we ought to live'.

Subsequently, by separating ethical agents from their ethical engagements, the insistence of immovable moral rules continues "the modernist ideal of getting it exactly right" (Heylighen et al., 2007:130). And so, from the comfort of moral certainty, 'manufacturing morality', therefore, can assume "that one's experiences or context have no effects on one's views of right or wrong" (Woermann, 2013:vii). The irony, however, is that "following a universal set of rules ... merely asks for calculation" (Cilliers, 1998:137), not choice. This shows no appreciation for the complexity of societal and socioecological relations and interactions, and thus hardly seems ethical at all. Moreover, to follow this faith in satisfying these apparently timeless moral facts is proof of a hypocritical position. After all, as Hattingh (1999:80) points out, the "ethics which recognise the rights of and dignity of persons, and which we accept as self-evident today ... gradually evolved to become a generally accepted and interwoven with the very fabric of our constantly evolving institutions, experiences and practices".

Nevertheless, the modernist understanding of ethics continues to belittle 'how we ought to live' by enforcing a certain value over another - applying rules to difficult decisions and immediately expecting justice, like applying facecream to acne and immediately expecting smooth skin.

If there were moral facts, as is argued by modernist ethicists, ethics would indeed just be a matter of right and wrong, no questions asked. This desire for an ethical equilibrium is what Woermann (2013:102) refers to as the desire for "an equalising justice or circular exchange between societal interest groups". There would be no moral dilemmas and no moral decisions. According to the deterministic reasoning of modernist ethicists, this would result in a perfectly just society of obedient individuals - the dream of order realised. The insistence on simplification is, therefore, guilty of further instilling the idea that "being ethical is easy" (Woermann, 2013:160). Indeed, anyone who has really confronted the difficulty of a moral dilemma will know that "we cannot talk about justice in the social sphere without realising 
that we are dealing with complex phenomena" (Cilliers, 2004:22). As such, it is argued by this thesis that a complete reliance on moral rules is an ignorant denial of complexity.

Of course, there is certainly some honour in some order, but ethical theories can never go so far as to base moral rules on a priori moral facts, since things like values, meaning and justice are not things that "exist in the way that planets and trees and spoons exist" (Rachels $\&$ Rachels, 2007:44). They are not waiting at the end of an equation. Therefore, the inflexible employment of moral rules is, albeit with 'noble' intentions, just another method of strict reductionism, which can only "result in the violation of something or someone that is not (or cannot) be considered of terms of that description" (Cilliers, 2004:23). Hattingh (1999:81) goes on to comment that, even if an a priori set of moral rules did exist, this would probably not realise the dream of order "given the manner in which the human mind actually makes decisions". As such, modernist ethical theories neglect the complexity of both our moral dilemmas and our decision-making.

The ever-approaching pandemonium of ecological ills, like food insecurity, resource depletion and climate change, has introduced the issue of inter-generational and intragenerational justice to public discourse. Indeed, this thesis acknowledges that, for instance, "we cannot get very far in discussing why climate change is a problem without evoking ethical considerations ... then we appear to need some account of moral responsibility, morally important interests and what to do about both" (Gardiner, 2006:398). However, without an appreciation of the ethical complexity in these contexts, academic inquiries will never be able to critically reflect, and thereby "engage with the problem of justice in a philosophical way" (Cilliers, 2003:9). It is, therefore, argued in this study that, if food systems scientists are unable to introduce an appropriate understanding of ethics that accounts for complexity, they will risk the integrity of our social system, and thus skew its expectation of what inter-generational and intra-generational justice might mean. Moreover, this will also have disastrous consequences with regard to how these inquiries understand the socioecological interactions of the world, through a time of drastic and unpredictable change, as the implications of such a society will equate to an "action that threatens sustainability" (Hawken, 2007:187).

By reducing the engagement with ethics to simply reporting on rules, the modernist influence in moral philosophy is thinning-out something so thick, and our academic inquiries are, therefore, not able to deeply reflect on the implications of their ethical actions and decisions. 
As such, modernist ethics ignorantly avoids the complexity of social and socioecological interactions, and so is also unable to account for the ethical considerations of others. Nevertheless, modernist ethical theories are content in only 'manufacturing morality', and ask only that individuals adhere "to the spirit and the letter of the law" (Chrispeels \& Mandoli, 2003:4). Therefore, traditional scientific thinking navigates its way through these turbulent times on a shaky moral high-ground, rather than sharing common ground for ethical deliberation.

\subsection{2: An Electioneering of Ethics}

From the perspective of a modernist moral philosophy, ethics has been a matter of building ethical theories based on the strictly reductionist assumption that we live and interact in "a black-white world of good and evil" (Norton, 1991:viii). The self-assurance that comes with this paradigm means that there is no place for debate or diversity in a dominant ethical positioning. By 'manufacturing morality', this thesis argues that the threat to appropriately understanding ethics is, therefore, further complicated by the competitive arrogance of an 'engineered ethics'.

Of course, any understanding of ethics will acknowledge the importance of saying something about value theory - that moral choices are made up of choosing one value over another "the two are, ultimately, inseparable" (Palmer, 2003:17). However, a value theory that commits to realising the dream of order cannot conform to "the nature of the inexistent" (Woermann, 2013:77). As such, the only order that is achieved is the ordering of winners and losers. In other words, when we are 'manufacturing morality', it is the conservative binary logic of 'thinking like a machine' that justifies submission to such a competitive electioneering of ethical theories (Warren, 1998). Modernist ethical theories, therefore, corrupt the innocence of value-hierarchical thinking, and keep certain values from our ethical decision-making, which deprives individuals from understanding the ethical position of the other actors in their moral dilemmas.

This conservative binary logic is represented in the dominance of theories of obligation in modernist ethics, which exclusively emphasise "impersonal duty, contracts ... and the calculation of costs and benefits" (Rachels \& Rachels, 2007:171). Such is modernist ethics' monopoly on morality, whereby the primacy of obedience equates to an absence of choice.

Of course, these values have their place - in the boardroom or on the battlefield, for example. However, by completely excluding care, compassion, tolerance and other values, such an 
attempt at offering an all-encompassing understanding of ethical complexity is problematic. Indeed, these overly-masculine ethical theories "are notoriously ill-suited to describing life among family and friends" (Rachels \& Rachels, 2007:167). It is a degradation of something that is unique to human beings - the moral dilemma - and, as a result, degrading to ourselves. After all, these rules are only a product of 'manufacturing morality' - a result of reductionism, not reality.

Nevertheless, as contexts have changed over time, these theories have necessarily been questioned and criticized. The nature of thinking about 'how we ought to live' means that the one-dimensionality of these modernist ethical theories cannot escape being compared with the complexity of real-life social interactions, and the effects thereof. After all, as said by Bryan Norton (1991:x), these polarised positions of moral authority "thrive only in ivory towers; when held up against the real world, they do not fit, and ... underneath, one usually finds a continuum with an oversimplification superimposed". As such, when the moral measures of 'how we ought to live' are discussed, the tendency is to "ricochet back and forth between apparently exclusive worldviews and sets of value assumptions” (Norton, 1991:9). This is ironic, once again, since the contingency of moral dilemmas that modernist ethical theory was trying to overcome has now become commonplace. The dream of order has become its own worst enemy, in that the certainty and supposedly solid foundations of modernist ethics have become splintered by ethical electioneering.

The debate in modernist ethics, however, is not one of constructive communication, but of competition. This is because of the conservative binary logic that modernist ethicists still insist on when they approach the theory of 'how we ought to live'. The ignorance of not engaging in ethical deliberation demonstrates an arrogance "which is exactly insensitive to the ethical dimension involved when we deal with complexity" (Heylighen et al., 2007:130). As a result, ethical theories avoid looking for common ground to work together and try and understand the complexity of our moral dilemmas, and stay "highly confrontational and adversarial, and also inconclusively, since they quickly degenerate into ideological stalemates" (Hattingh, 1999:78-79). The continual conflict of ethical positions, therefore, adds to "the popular image that philosophers tend to talk to themselves, turning their backs on a world which hopes to gain from the insights they can bring" (Hattingh, 1999:71). The result of this is an appropriate engagement with ethics is further marginalised from academic inquiries, which only stresses that individual's values and ethical assumptions are of no concern when engaging in scientific research. As such, an 'engineered ethics' only reinforces 
the vicious cycle of strict reductionism, which is unethically stubborn in its "denial of creative change" (Heylighen et al., 2007:120). This is, indeed, something of which academia should be ashamed, and something which we urgently need to address.

This is wholly misplaced in the context of sustainability, since the decisions that members of the public, academics, or anyone in society as a whole will have to make, will not be simple 'either/or' choices, "but will involve choosing between options that have different benefits and costs, for different people at different times" (Clayton \& Radcliffe, 1996:11). If academic research remains unreflective and inconsiderate, it cannot claim to be committed to the problems of sustainability transitions or food security in an ethical way, since only one group or argument will benefit from an unquestioned ethical framework, where one value rules over another. And so, without any critical communication and engagement with our seemingly incompatible ethical positions, these difficult decisions are "liable to remain blinkered and uninformed" (Blewitt, 2008:29). Furthermore, this is detrimental not only to the understanding the ethical complexities of the global polycrises, but also to the multilayered complexity of the contexts in which these crises emerge. After all, ethical contexts cannot be appreciated as something separate from ontological and epistemological contexts.

The difficult decisions that moral dilemmas demand of ethical agents are only deepened by the walls that modern moral philosophy has put up between ethical positions. Indeed, this is further problematised by the fact that these 'moral wars' are something that "academic and social commentary ... has accepted and even reinforced" (Norton, 1991:11). As long as scientists' engagement with ethics is as an attempt to impress a moral high-ground, it will never be able to understand the complexity of what it means to address 'how we ought to live'. Subsequently, researchers will also never appreciate the responsibility- and opportunity - of what it means to be alive today.

\subsection{3: An Evasion of Ethics}

If today's social and socioecological behaviour represents moral responsibility, then, at the very least, moral philosophy must rethink how 'responsibility' is conceptualised. This thesis emphasises that this misunderstanding plays a large part in embedded poverty, class inequality, and food insecurity. So, in order to round-off this critique, this thesis must investigate where modernist ethics' understanding of moral responsibility stands in light of these tragedies. After all, "to the extent that they exist ... they're choices" (Chomsky, 2012:63). 
The fact that we can acknowledge that things such as ethics, moral order and moral rules do exist shows our appeal for displaying a certain socially acceptable and respectable behaviour. However, even with the extra considerations that come with the introduction of new technologies, new ideas and society's changing values, "few of us actively engage in an ethical analysis of our actions or can provide reasons for the choices we make" (Chrispeels \& Mandoli, 2003:4). In fact, when ethics just becomes a matter of responding to rules, "in such circumstances, there is no responsible action" (Woermann, 2013:111). Of course, it is easy to blame the rules, but blame only has substance when the philosophical context thereof is understood. It is, therefore, not so much the ideal of moral rules that is at fault, but rather the modernist paradigm of thought that believes these rules to be immovable and based on moral facts. In a critical reflection of the expectations implied by an 'engineered ethics', Cilliers (2004:20) says that "if one's understanding of ethics involves the combating of real, contingent injustices, one can argue that the modernist position is actually a way of circumventing ethical responsibility". Is argued that the resulting behaviour is, therefore, far from the desire to 'do good' that we strive for - it is, if anything, an evasion of that attempt at ethics.

To honestly understand and encourage ethical behaviour, we have to appreciate the responsibility of our own moral decision-making. However, in an 'engineered ethics', the responsibility of the calculative choices that are made in moral dilemmas are far removed from the actual choices themselves, since that responsibility has been moved to a metaphysical position, or a "supra-individual level" (Bauman, 1992:xxii). This works well for those who want to do away with the distress of dilemmas, and for those who want to direct our decisions, but to call this behaviour 'responsible' seems contradictory to the appeal of 'how we ought to live'. It is, therefore, problematic to expect appropriate ethical action if ethics is thought of in a way that disregard the complexity of what it means to act responsibly. This is because "a transcendental notion of justice is useless in practice since we do not know what it is" (Cilliers, 2004:23). Indeed, this passivity offers only a "blind intelligence [that] fosters unconsciousness and irresponsibility" (Morin \& Kern, 1999:128). Nevertheless, it is the conflicting and manipulative influence of 'manufacturing morality' that still manages to dominate our interpretations of ethics, and thus our interpretation of responsibility.

As seen in the morally questionable behaviour of society that is present today, "the effects of modernist ethics are unfortunately not confined to philosophical positions" (Cilliers, 
2004:20). Modern systems of law, politics and economics go about their business in confidence that they are firmly on a moral high-ground, and this influence has had a 'trickle down' effect, extending to the norms of our general societal behaviour. The responsibility of ethical action has, therefore, been replaced by what Stephen Gardiner (2006:408) calls the "manipulative or self-deceptive behaviour ... of moral corruption". The implications of the stringent instructions have led to an overemphasis of values that are overly "self-assertive" (Capra, 1996:9-10), and which have clearly been inadequate in the context of a complex society and world. The influence of modernist ethics has seeped down to everyday interactions, the result being what has been referred to as the "neoliberal ideology';"to just take care of yourself and forget about anyone else" (Chomsky, 2012:73).

Of course, when reducing mountains to machines, this behaviour is apparent in the unreflective and exploitive engagement with the Earth. However, whilst many individuals and economies have benefitted from this exploitation, much more cultures and populations have suffered because of our electioneering of these self-serving values. It might be thought that the West lives in the 'civilised' world, but even in the most industrially developed of nations, this grossly impassionate and passive behaviour was all too commonplace not long ago, as both women and indigenous populations were regarded as second-class citizens (Chomsky, 2012). More heartbreakingly is that the bitterness of this behaviour still lingers in the dark corners of their communities, even when these rules have changed. Think of the injustices during apartheid - where white people were allowed to treat black people like subhumans "by uncritically remaining within the confines of law" (Cilliers, 2004:4) - and how those race relations still remain in a supposedly free and democratic South Africa. This puts in a dangerously unsuited position with regard to guiding society through sustainability transitions.

To engage with the moral responsibility of ethical decision-making requires critical reflection. This thesis argues that it is necessary to slow down the chatter of the "machine mind' and open academia up to the depth of its ethical context. However, in today's "cult of speed" (Cilliers, 2006:108) there is never time for this. In an 'engineered ethics', therefore, there is no reflection, only reaction. As such, "this move away from reflection to immediate response" (Cilliers, 2006:108) is an undignified and inappropriate approach to addressing something that says so much about what it means to be human. The denial and avoidance of ethical complexity is, therefore, a denial and avoidance of our humanity. 


\section{3: Manufacturing Morality in the Context of Food Systems}

It is important to reflect on the dominant understanding of ethics, so as to provide the necessary space from which a way of thinking about 'how we ought to live' that acknowledges the complexity of our socioecological interactions can be introduced. However, given that this is something that requires a committed and academic mind, it is suggested that this critique of the modernist understanding of ethics in sustainability transitions is complemented by reflecting on this understanding in the context of the food system.

When we are 'manufacturing morality' in the context of food systems, it is believed that there are unquestionable and objective moral truths, from which the necessary ethical action to 'feed the world' can be directed. Indeed, modernist food system ethics is claimed to have predominantly utilitarian roots, which adheres to the moral rule "that when evaluating an action we judge its outcome" (Chrispeels \& Mandoli, 2003:5). As such, in this unreflective short-sightedness, there is a "moral confidence" (Chrispeels \& Mandoli, 2003:4) that is expressed in the 'duty' to maximise the production of food. So, as long as the 'end' of increased yields is achieved, then any 'means' is justified, and as such, this interpretation stays strictly within the modernist 'production paradigm'. For example: the industrialised farming of battery chickens; the heavy dosage of pesticides and herbicides to keep food from naturally decomposing; the genetic engineering of foods to appeal to aesthetics; and the destruction of biodiverse rainforests to plant soy or make grazing land for cattle that will feed the unhealthy diets of the West (Battersby \& McLachlan, 2013).

Of course, it is important to emphasise the consequences of our actions, and there is a moral integrity in 'feeding the world'. However, as argued earlier, a sustainable food system will have to represent more than just an increase in food production. It is, therefore, ethically unsound in thinking that moral responsibility is simply to maximise output. Moreover, this ethical position assumes an objective knowledge of future effects and influences, which is insufficient in addressing the uncertainty and ever-changing contexts of sustainability transitions. There is no contextual acknowledgement of how different our moral considerations and moral responsibility would have to adapt with regard to the food systems' "rapidly changing context that involves both 'long wave stresses' such as climate change, and 'short wave shocks' such as food price volatility” (Drimie \& McLachlan, 2013:218). 
However, many individuals and organisations involved in the study of the food system still believe themselves to be acting from a moral high-ground. According to agriculturalist ethicist Paul Thompson (1998:13), proponents of the 'production paradigm' may well "have been seduced into thinking that so long as they increased food availability, they were exempt from the constant process of politically negotiating and renegotiating the moral bargain that is at the foundations of the modern democratic society". Indeed, as told by author Robert Zimdahl (2002:46), those who adhere to this way of thinking about understanding ethics in food systems, "have not taken the time to articulate any value position other than the value of production". Therefore, due to the arrogance of 'manufacturing morality', those committed to food security are, nevertheless, incapable of engaging ethically in issues of food systems. Any progress towards realising sustainable food systems is "characterized by political stalemate" (Henry, 2009:131), and as a result, our understanding of the wider complexity thereof is reduced.

As an example of this, we need only recall the earlier controversy, which linked Monsanto products to serious health concerns (Séralini et al., 2012). Since the study's publication in the Food and Chemical Toxicology journal, there have been numerous criticisms that point out its apparent "breaches of ethical standards" (Robinson \& Latham, 2013). According to these advocates of genetic engineering, there was an unquestionable ethical line that the academics had crossed. This should reveal how such an argument is reminiscent of 'manufacturing morality', in that the critique appealed to transcendental moral standards. Of course, the point here is not to try and justify the ethics of the study, but rather to point out that the criticism came from a position of an 'engineered ethics'. However, in the same light, the moral dilemma of genetic engineering is not a dilemma we can remain ignorant about, since we must also accept that without it, those impoverished communities in drought-stricken areas, for example, would be completely helpless. This reveals the complexity of such an issue, and we do not have the luxury of objectivity to claim what is 'ethical' and what is 'unethical'.

Moreover, the complexity of moral dilemmas that espouse the difficulty of choosing equally valid but opposing norms and values demonstrate that the ethical issues that confront those working towards sustainable food systems cannot be addressed in isolation, but "pertain to the entire complex of agricultural practices and to the transition from production to sustainability" (Chrispeels \& Mandoli, 2003:9). As a result, the approach to ethics in the food systems context cannot be a matter of "exclusive choices ... [from which] I must choose between two inadequate languages to express my indignation" (Norton, 1991:6), since 
contexts change and values, and therefore, the reasons that satisfied an earlier moral choice may not apply. Instead of making claims of moral authority from positions of supposed ethical objectivity, there is a demand to, rather, deliberate on the moral dilemmas with which we are faced (Zimdahl, 2002). The richness of ethics is, after all, in our ethical questioning, not our answers.

Nevertheless, the simplification of ethics in food systems continues, and its impact extends beyond those involved in food production. Typical of the 'machine mind', is that the modernist market-orientated understanding of food systems is represented by an anthropocentric setting of consumers and producers, and so, moral considerations towards the ecological setting are disregarded. However, more interestingly, this thesis argues that this producer-consumer relationship is a linear and one-way relationship in character - typical of modernist thinking - and subsequently elucidates how consumers have also passively accept the ethical actions of those involved in the 'production paradigm'. This has resulted in an unreflective 'consumer paradigm', which is characterised in the fast-food culture - "a cult of speed" (Cilliers, 2006:108). We have no idea where we get our food from, how it is made or what is in it - and we do not care, since we do not understand that to be part of our moral responsibility. However, this unreflective decision-making "makes us ill, divides us, and harms our planet" (Battersby \& McLachlan, 2013:716). It is, therefore, notable how the food systems have had an effect on wider socioecological systems, as well as how the role that the 'production paradigm' has played in our understanding that 'the values needed to support a sustainability transition are not prevalent within contemporary society" (Henry, 2009:134). As such, this thesis further stresses how important it is to address how we understand ethics when we work towards sustainable food systems.

It is necessary to rethink the moral certainty of the 'production paradigm' that those involved in the food system have long held absolute, and acknowledge that an 'engineered ethics' is insufficient in dealing with the difficult decisions we have to make in realising sustainable food systems. Of course, adopting a way of thinking that addresses ethical complexity will be significant learning process, but just like in the contexts of food systems, "ethics and social learning will be necessarily an important part of any decision-making process" (Blewitt, 2008:43). Of course, responsibility cannot be shifted onto transcendental ethical standards, this expectation applies to every actor in the food system, since "failures of group decisionmaking ... is of course related to the problem of failures of individual decision-making" (Diamond, 2005:420). 
So, in order to understand ethics in sustainability transitions, especially in the food systems context, a thinking that embraces the ethical complexity of our moral dilemmas must be introduced. Such an understanding will no doubt be complex itself, but it is necessary to first lay appropriate foundations from which we can acknowledge the complex nature of our socioecological systems in changing contexts. Thereafter, we will be able to reflect on the demands of an appropriate understanding of moral responsibility in sustainability transitions.

\section{4: Chapter Summary}

This chapter has critiqued modern moral philosophy's inappropriate approach to the question of ethics. This has provided the necessary space from which a more appropriate way of thinking can be introduced that is more fitting in the context of sustainability transitions from the lens of complexity and from which an apt and contextualised understanding of ethics can be provided.

The first section presented the imagery that demonstrates this understanding of ethics' disregard for complexity, namely 'manufacturing morality'. Following this introduction, the next three sub-sections saw to unpack the fundamentals and implications of modernist ethics.

Firstly, through the imagery of 'an engineering ethics', the motivation and method of modernist ethics' approach to moral dilemmas was presented, which showed a continued ignorance towards complexity. Secondly, through the imagery of 'an electioneering ethics', the investigation revealed how modernist ethics arrogantly confronted the contingency of difference in an ethical context and contrasting positions. Thirdly, through the imagery of 'an evasion of ethics', this critique followed-up on the previous two sub-sections' allegations, by addressing the implications thereof, which focused on how modernist ethics corrupts the notion of moral responsibility.

The last section of this chapter presented a contextual reflection on the modernist understanding of ethics with regard to food systems, and concentrated on how this understanding affects academic interest in realising sustainable food systems. 
Part 2: The Mountain Mind and an Emerging Ethics 


\section{Chapter 4: The Mountain Mind - Imagining Complex Thinking}

\section{1: Chapter Overview}

In short, this chapter presents the beginning of the philosophical exploration on how to think about ethics in sustainability transitions - from the perspective of complexity. To begin with, therefore, it is necessary to lay appropriate foundations of thought that will inform such an appreciation, through a conceptual analysis, from which a study of sustainability transitions can be appropriately positioned. After doing so, a suitably complex approach to the question of ethics can be introduced.

The first section will present the imagery that represents a way of thinking that, in contrast to 'thinking like a machine', attempts to account for complexity, namely 'thinking like a mountain'. From this introduction, the next three sub-sections will shed light on the principles of this complex way of thinking, and the implications thereof.

Firstly, the revolutionary ontology and epistemology of complex thought is introduced, through the imagery of 'a renaissance in reductionism and onwards'. Secondly, through the imagery of 'binding binaries and beyond', it is investigated how this way of thinking embraces and depends upon the contingency of difference and the views of others. Thirdly, through the imagery of 'the mountain mind in modesty', this sub-section introduces the inherently ethical element of this paradigm, and therefore, complements the implications of the previous two sub-sections by commenting on the necessary attitude of modesty.

The last section of this chapter provides a contextual reflection of this paradigm of thought with regard to food systems, and focuses on how this complex way of thinking will affect how academic inquiry can contribute to realising sustainable food systems.

\section{2: Thinking like a Mountain}

An appropriate paradigm of thought will have to address the complexity of our realities, which is "perhaps the most essential characteristic of our present society" (Heylighen et al., 2007:117). Of course, the move to acknowledge the beautifully messy will "not lead us out of the woods, but it should enable a discussion that is more fruitful"' (Cilliers, 2000b:8). So, instead of 'thinking like a machine' - the strictly reductionist way of thinking about the world and how we relate to it - this study proposes that a more appropriate approach to sustainability transitions should rather be 'thinking like a mountain'. 
For centuries we have shied away from opening up to contingency, and refused to offer complexity any space in our investigations. In recent years this has changed, however, as academia is slowly learning the importance of acknowledging complexity and its significance (Audouin et al., 2012; Capra, 1996; Cilliers, 1998; Clayton \& Radcliffe, 1996; Emmeche, 2004; Harding, 2006; Hawken, 2007; Lyotard, 1984; Max-Neef, 2005; Morin, 1992; Nicolescu, 2002; Swilling and Annecke, 2012). Indeed, the recognition that living systems do not function under the same conditions as mechanistic systems led biologist Ludwig von Bertalanffy to note "that living systems, unlike their mechanical counterparts studied by Newtonian science, are intrinsically open” (as quoted in Heylighen et al., 2007:121). The implication of this revelation has meant that we seriously need to rethink the strictly reductionist ways in which think and reason about the world. The imagery of 'thinking like a mountain' draws from the writings of Aldo Leopold (1991), who suggested that, in order to understand the complex nature of socioecological systems, one must adopt a similarly dynamic way of thinking that would complement the dynamic processes of such a socioecological system, like a mountain. Instead of short-term simplification, 'thinking like a mountain' would emphasise a slow process of learning about the ever-emergent relationships that characterise a phenomenon in its context. Hattingh (1999:72) refers to this as thinking "in terms of ecological and geological time: the time it [takes] to evolve plants and animals and behaviour patterns appropriate to the conditions of the mountain slopes". Although a 'machine mind' paradigm might contest such a claim, it is necessary that "our relation with a complex world and a complex Nature, requires complex thought” (Max-Neef, 2005:14).

However, whilst we may realise that we should be thinking more like a mountain than a machine, we must also realise that this will not gift us with complete understanding of the complexity of systems, because complexity is itself "incompressible" (Cilliers, 2004:22). After all, as Leopold (1991:137) has written, “only the mountain has lived long enough to listen objectively to the howl of the wolf'. Nevertheless, whilst we should refrain from reverting back to the one-dimensionality of strict reductionism, 'thinking like a mountain' does not give up on the gift of reason. On the contrary, this study looks to introduce an argument that provides the necessary space for "an intelligent and sophisticated reductionism” (Clayton \& Radcliffe, 1996:17). The paradox of 'thinking like a mountain', therefore, is that it reveals the inescapable "need for reduction, while making the strategies for such reductionism transparent" (Audouin et al., 2013). This would, therefore, differ from 
a reactionary anti-reductionist argument, and would embrace a kind of reflexive reductionism as is argued by Audouin et al. (2013).

When we are 'thinking like a mountain', we are acknowledging and embracing something that has long been excluded from our academic inquiries. As such, we are fundamentally challenging a number of deeply embedded assumptions we have about ourselves, and how we relate to a supposedly separated and simple world. This revolutionary shift in thinking that is introduced by an acknowledgement of complexity is, therefore, what Capra (1996:4) had in mind when he announced that "we are now at the beginning of such a fundamental change in worldview in science and society, a change of paradigms as radical as the Copernican revolution".

\subsection{1: Towards a Renaissance in Reductionism and Onwards}

The openness of socioecological systems means that we are not just dealing with systems in general, but with complex systems. As such, if we are to say anything about the world and how we relate to it, we will have to adopt a soft and sensible form of reductionism that somehow respects the irreducibility of complexity and keeps it alive. The perspective of systems thinking still provides a possible way of thinking appropriately about complexity that does not kill it. However, this will mean moving beyond the 'parts-whole' simplification.

The importance of surpassing this 'parts-whole' simplicity is evident when it is acknowledged that, in different contexts, 'parts' are 'wholes' and 'wholes' are 'parts'. For example, if we want to know "with regard to Homo, which of the following is the system: the society, the species, or the individual?" (Morin, 1992:375), we are unable to keep one claim 'truer' than the other. It is, therefore, wholly inadequate and quite crude to talk just about 'parts' and 'wholes', since there is so much more to the beautifully messy than just 'things' there are also 'happenings'. So, by exploring the importance and effects of context - an influence long-forgotten by the 'machine mind' - our inquiries are able to shed light on these 'happenings', or what Urry (2005:5) refers to as "system effects that are different from their parts".

When inquiries study and appreciate phenomena in their context, it is soon realised that it is not the 'parts' or the 'whole' that is of interest - or worth the worry - but rather how these 'parts' and 'wholes' interact and relate to each other. It is this different way of seeing and thinking about the world that "seems to explain the emergence of organisation in any domain 
or context: physical, chemical, biological, psychological or social" (Heylighen et al., 2007:126). Indeed, when we start to identify socioecological systems to be composed of more than just 'bits' and 'pieces', but of contextualised interactivity between the 'bits' and 'pieces', we begin to answer "a fundamental philosophical question ... [about the] apparent intelligence that we see around us" (Heylighen et al., 2007:126). Understanding the beautifully messy from the perspective of systems thinking, therefore, "means understanding relationships" (Capra, 1996:298). As such, this thesis argues that sustainability transitions can be understood to be about mending and sustaining the relationships between the complex social and ecological systems that are conducive to their interrelated vitality.

However, and importantly, these are contextualised relationships. As such, it is always necessary to emphasise "the importance of contingent factors, of considering the specific conditions in a specific context at a specific time" (Cilliers, 2001:145). So, rather than reducing an isolated phenomenon to its componential 'parts' or its totalising 'whole', 'thinking like a mountain', introduces a soft and sophisticated reductionism, which would entail seeking out "the relation of inseparability and of inter-retro-action between each phenomenon and its context and of every context with the planetary context" (Morin \& Kern, 1999:130). This means that academic inquiries must allow socioecological systems and their revitalising relationships to expose themselves in the research process. It is, after all, this openness to emergence that bears the fruitfulness of the 'mountain mind'. In this light, 'thinking like a mountain' would necessarily acknowledge both "the downward direction of reduction or analysis, and the upward direction of holism or emergence, as equally important for understanding the true nature of the system" (Heylighen et al., 2007:122). The contextualised relationships are thus an emergent property of the dynamic processes of organisation actors, parts, wholes and events.

Of course, 'thinking like a mountain' is a still reductionism of complexity, but it is a 'light' form of reductionism that works with complexity, not against it, and thus provides space for socioecological systems to express their dynamism - it lets the 'happenings' happen. As such, whilst nothing absolute or complete can be said about complexity, this does allow us to say something about 'general complexity' (Morin, 2007). It is no longer about mastering and controlling, but about monitoring and cooperating. Therefore, from the perspective of systems thinking, an understanding of complexity introduces an appreciation of the mystery of life as "a cluster of emergent qualities resulting from the process of interaction and organization between parts and the whole" (Morin, 1992:374). And so, in contrast to the 
blurred lens of the 'machine mind', which sees the beautifully messy as a separated space of lifeless objects, the 'mountain mind sees a vibrant community of beautifully messy relationships - and we are part of that community!

Indeed, it is this inclusionary perspective that "roots our own complex body more firmly in the natural world" (Emmeche, 2004:43). The inclusionary perspective, which is a result of thinking like a mountain, influences even how one sees something essential, such as self identity. In explaining how we understand ourselves in complex contexts, Cilliers (1998:116) references the work of Lyotard (1984), saying that "the self is understood in terms of a "fabric of relations', a node in a network". Subsequently, one's own identity, as a scientist or as a politician, a consumer or a producer, a son or a daughters, is neither predetermined nor fixed, but "constituted in a complex network" (Woermann \& Cilliers, 2012:416). In contrast to the 'centred self', it is, therefore, important to emphasise the 'complex self' as a participant contextualised in socioecological systems as well - decentralised, interconnected and interdependent, as opposed to centralised, separated and independent. And given the open nature of complex systems, a participatory and inclusionary approach to the world "is in fact the only available option" (Harding, 2006:33).

Importantly, when it comes to studying sustainability transitions from a complexity perspective, as alluded to before, this reciprocal interdependence means that researchers share the same contexts of the systems they study, as "outputs of parts of the systems become inputs of others" (Lotrecchiano, 2010:39). We, therefore, have no scientific high-ground from which we can ascertain any knowledge that is free from the contingency of subjectivity. As such, when invested in the study of complex phenomena in complex contexts, we are inevitably dependent on reductionist interpretations and therefore, "cannot do other than model and exclude" (Woermann, 2013:47). This creates the boundaries with regard to the context of our knowledge, and the frame of boundaries in which we are able to reasonably discern the meaning of something. The consequence of this is that "uncertainty, indeterminacy, randomness, and contradictions appear not as residues to be eliminated by explanation, but as ineliminable ingredients of our perception" (Morin, 1992:381).

This way of thinking about systems that moves beyond the classic 'parts-whole' mentality "offers a way to gain an overview of complex systems" (Kagan, 2010:1096). As the changing contexts influence the relationships between and within the social and ecological systems, so too does this change an understanding of the beautifully messy. So, rather than feeding the 
'machine mind' monster's desire to compartmentalise and control, this makes room for the 'mountain mind' to approach the socioecological systems with awe and wonder.

\subsection{2: Towards Binding Binaries and Beyond}

Since the emphasis in the 'mountain mind' is on respect and appreciation, this will mean that we will have to rethink how we approach that which has previously stood in the way of that desired control and objectivity we once emphasised - differences. Although there is an explicitly ethical element in this inclusive approach, this is not just sympathetic consideration for the contradictions and absurdities of the beautifully messy. To account for the subordinated 'halves' of apparent non-existence, is part of the ongoing search to understand more richly how the interactions allow for complex systems to organise themselves.

An appreciation of the complex organisation of systems will have to reimagine the dualistic separations invented by the 'machine mind', not as simplified assimilated wholes, but as "a complement of two entities acknowledged as separate, different, independent, yet in relationships" (Warren, 1998:263). This approach is more engaging and welcoming than the conservative binary logic. Whilst the differences are still recognised, the 'mountain mind' also recognises and respects their interdependency. They are co-identifying - they are coconstituents. Cilliers (1998:138) comments on the importance of differences "as that which constitutes our humanity". From this perspective, this thesis highlights how the different terms themselves are not as relevant as the relationship of difference between the terms.

In contrast to the conservative binary logic of the 'machine mind', this study will, therefore, propose that this understanding of identifying and embracing differences be referred to as a 'liberal' binary logic. This can be related to the differential logic of Derrida (1978), who uses the term différance to "signifying systems are constituted by a difference that both separates and joins" (Woermann, 2013:60).

Of course, this will still represent a hierarchical relation, but the 'mountain mind' entertains no stage of oppressive domination - the relation is more horizontal than vertical. Such an understanding of hierarchy, therefore, represents systemic interactions between two or more interpenetrating positions that "may be fairly limited or so extensive that it becomes difficult to typify the hierarchy accurately in terms of prime and subordinate parts" (Cilliers, 2001:143-144). It is this appreciation of inseparability that allows academia to move beyond the dominant 'either/or' divisions of modernist thinking. By appreciating that the seemingly 
opposing terms are 'joined at the hip', academic inquiries are now able to reveal how 'thinking like a machine', itself, "undermines the philosophy it asserts, or the hierarchical oppositions on which it relies" (Culler, 2008:86), and as such, gloriously uncover the inadequacy of the conservative binary logic.

The demands of acknowledging complexity, and moreover, acknowledging complex systems, was never going to come from a paradigm of simplification - for very obvious reasons. These demands are further stressed, when it is understood that the complexity of socioecological systems are not made up of only two sides. It is part of a necessary reductionism to frame it so, in order to shed light on the 'general' complexity. The result is that, rather than the universalising comfort of pseudo-order that was promised by the 'machine mind', this would mean that the 'mountain mind' would entail "uncertainties and antagonisms by bringing together terms that are mutually interconnected" (Morin, 1992:378). This is of epistemological significance, in that academia will have to integrate a creative way of thinking in our complex paradigm of thought, which supports "a dynamic feedback loop among [these] terms which are simultaneously complementary, competitive, and antagonistic" (Morin, 1992:383). Nevertheless, we will never be able to "conceive of our earthly identity and of anthropolitics without a thinking capable of relinking disjointed nations and compartmentalized areas of knowledge" (Morin \& Kern, 1999:129).

The importance of embracing this complex way of thinking about differences is unmistakable with regard to our academic inquiries. Since researchers are embedded in the context of their own studies, any position taken will always be differentiated from other ways of seeing and being, which limits the insight into anything complex. It is, therefore, reasonable that researchers open themselves up to working with other approaches, while maintaining their own academic identities, "not in order to see which one is best, but in order to help us to explore the advantages and limitations of all of them" (Cilliers, 2001:136-137). It is, however, not suggested that specialisations are discarded, but rather to reveal the idea that these specialisations will have more to offer when exposed to a wider context of cooperation. In this light, disciplinarity, interdisciplinarity and transdisciplinarity should complement each other, since such collaboration would generate "reciprocal enrichment that may facilitate the understanding of complexity" (Max-Neef, 2005:15). As such, academia should, therefore, not be understood as a linear and lonely road towards truth, but as 'teamwork'; "a process of working towards finding suitable strategies for dealing with complex phenomena" 
(Woermann \& Cilliers, 2012:406). This is complemented by the notion that science is, after all, "a tumultuous building site" (Morin 2007:21).

Nevertheless, given that academia is mostly still stuck 'thinking like a machine', it should explicitly focus on the notion of working towards working together. This is especially imperative in sustainability transitions, since much of our problems are as a result of our compartmentalised way of thinking. There is little debate, therefore, that in order to address our global polycrises, we are expected to make significant progressions in scientific understanding of the world. Encouragingly, however, is that such progress, be in the form of technologies or ideas, "is often made when attempts are made to bridge into the domain of other disciplines" (Clayton \& Radcliffe, 1996:17). Therefore, to build a better socioecological relationship, the opportunities of offering contextualised "real-world solutions require dismantling some of the boundaries between disciplinary and programmatic fields" (Drimie $\&$ McLachlan, 2013:218). In other words, in remedying the relationships of academia, the approach of 'thinking like a mountain' has the potential to also remedy our socioecological divisions.

As such, it is proposed that academic inquiries into sustainability transitions can now approach the beautifully messy not with an 'either/or' sight, but with 'both/and' eyes. This openness to all areas of academia supports "capabilities for systems thinking, because it trains individuals and societies to think of themselves in relationship" (Kagan, 2010:1096). However, it should not be seen as a practice that leaves the organisational elements of science behind, since "searching for common structures across individual theories and local fields of knowledge is a truly legitimate aim of science" (Emmeche, 2004:24).

\subsection{3: Towards the Mountain Mind in Modesty}

In our acknowledgement of the complex nature of socioecological systems, there is still the insufficiency of any reductionist strategy, like 'thinking like a mountain'. However, it is not enough to wallow in this acknowledgement. Complexity thinking, therefore, requires a critical engagement "with the status and limits of our knowledge claims" (Woermann \& Cilliers, 2012:404). Not only will this keep academia constantly reminded of these contingencies, but it will also keep it from slipping back into the arrogance of 'thinking like a machine'. 
The paradigmatic shift in thinking that the lens of systems thinking has introduced is certainly "a different manner of seeing the world" (Max-Neef, 2005:15). However, it must be remembered that it is, of course, just one way of seeing the world - it is still just a lens of complexity. When this lens is introduced, therefore, it will never be able "to escape the moment of interpretation and decision" (Cilliers, 2000a:31) that emerges from all knowledge claims. This, in turn, offers us what Nicolescu has called 'in vivo' knowledge; that which "corresponds between the external world of the object and internal world of the subject ... including a system of values" (Lotrecchiano, 2010:41). As such, the thesis emphasises that there is an inevitability of ethics in addressing complexity, since "our decisions always involve an element of choice that cannot be justified objectively, but are, in part, based on normative judgements" (Woermann \& Cilliers, 2012:404). This uproots the foundations of 'thinking like a machine' that have relied on a supposedly value-free prescription in its dream of order, and subsequently, revealing that our ontological and epistemological questions should be considered alongside our ethical questions.

The pervasive presence of ethics in an interpretative interaction with the world "is an inevitable result of the inability of a theory of complexity to provide a complete description of all aspects of the system" (Cilliers, 2000a:30). For this reason, it must be stressed that acknowledging the ethical implications of our inquiries "is a structural element of complexity thinking" (Woermann \& Cilliers, 2012:404). It will, therefore, be necessary to explicitly engage with this experience as part of academic rationality, as "we cannot properly understand the production of scientific knowledge without considering the role that normative theories play in our interpretation of real-world events" (Henry, 2009:136). However, this will only be elaborated on later in the study, and for now, this thesis will concentrate on the implications of our subjectivity and implicit normativity. In light of this, it is important that we highlight the need to counter the unintended consequences of these implicit normative impulses with the urgent introduction of a self-critical rationality to the 'mountain mind'.

Scientific thinking should, therefore, be presently inclined to be just as sceptical about its own contingent subjectivity and shortcomings as it is about other things, like its past shortcomings. This would suggest that, more than just being self-reflective, an appropriate approach to complex systems would, in fact, have to be critically self-reflective. Indeed, such a way of thinking is "the outcome of acknowledging the irreducible nature of complexity" (Woermann \& Cilliers, 2012:406). Of course, to be doubtful of our own reasoning may seem 
paradoxical, but an honest appreciation of contextual complexity requires a thinking that "is open and enters into dialogue with a reality that resists it" (Morin \& Kern, 1999:129). As such, it is sensible, not silly. Only by understanding and confronting scientific thinking's historical identity - our modernist deficit - can today and tomorrow's academic inquiries make "progress in ignorance" (Morin, 1992:378). Indeed, this may very well be supported by a liberal binary logic, in that this progress may emerge exponentially from this logic's openness and the constructive criticism from others that would follow, and vice-versa.

By introducing a rationality of critical self-reflection (Preiser, Cilliers \& Human, 2013), a space opens up that would acknowledge an inherent vulnerability to making uninformed decisions - or simply put, mistakes. The significance of critical self-reflection can, therefore, not be more stressed, especially given the pressures of possible socioecological collapse. After all, an understanding of complex systems teaches that, due to the non-linearity of their interactions, "small causes can have large effects" (Cilliers, 1999:123). And because of the phenomenon of feedback loops, these effects can sometimes multiply a problem, instead of solving it. What this means is that we are dealing not only with the limits of our knowledge claims, but also our limited knowledge about the impact of our knowledge claims. In the context of sustainability transitions, the argument for this epistemological jump is, therefore, a plea for caution in the midst of necessary action. As such, it is important that when engaging in academic inquiries, "we have a responsibility to make our research framing strategies explicit" (Audouin et al., 2013).

This is, of course, not an argument to denounce our individual agency, since the value of our subjectivity is just as critical as our own criticism thereof. Indeed, given the nature of complex systems in which we exist, "you can only understand that of which you become a part" (Max-Neef, 2005:15). Therefore, similar to the technological understanding of the word, it is understood that placing too much emphasis on "the precautionary principle stifles innovation and runs contrary to the human desire to innovate so as to better our lot on Earth" (Chrispeels \& Mandoli, 2003:8). It is, therefore, important that this self-critical rationality does not overwhelm research of sustainability transitions, to the extent that it stops us completely in our tracks. A deafening defeatist attitude has no place in confronting complexity. Therefore, in order to make the necessary progressions in science and culture, the modest approach to thinking about complexity must be coupled with bold and courageous action, by which research can necessarily transgress its self-doubt, and thereby "violate accepted or imposed boundaries" (Woermann, 2013:76). Again, it is through harnessing a 
liberal binary logic that it is understood that "modesty and transgressivity go hand-in-hand" (Woermann, 2013:77).

Still, there will always be laggings and loose-ends in our knowledge claims, which can only further problematise our understanding of complex systems - this is the complexity of studying complexity. So, to remain aware of the inadequacy of our knowledge claims is also to remain humbly aware that this is a contingency that cannot be overcome. As noted by Degenaar (1993:51), the revolutionary thinking that characterises the paradigm of complex thought must remain "conscious of the fact that the new dispensation can itself fall into absolutism ... [and so] eternal vigilance, continually holding off gods and tyrants, becomes part and parcel of this revolutionary attitude". The emphasis of continuity satisfies both the honest impetus of this self-critical rationality, but also its logic, "which functions as a recursive modality" (Woermann, 2013:162). The 'mountain mind', therefore, allows us to confront the 'machine mind' and its dream of order, and thereby awaken the dormant owls of Minerva from a coma. In other words, an appropriate approach to complexity is not to overcome it, but to try and keep up with it.

The burden of continuous modesty is arguably a deserved burden, given the state of socioecological systems and the anthropological role therein. However, paradoxically, it is also necessary to recognise that this burden is also a skill, since a thinking that is comfortable with the confusion of continuous self-criticism, will most certainly help us in understanding the character of sustainability transitions, which represents "apparently paradoxical reconciliations" (Kagan, 2010:1094). The insight received by a critical self-reflection has the potential, therefore, of providing academia with "important opportunities for fashioning ways of coping with future surprises and unknowable risks through intentionally building up resilience in socio-ecological systems" (Blewitt, 2008:43-44). This potential is further enriched when disciplines partner with other disciplines in critical dialogue. In this regard, thinking about sustainability transitions can only be satisfied by long-term thinking, as oppose to the short-sightedness of 'thinking like a machine'. It is, after all, "an unreflective fastness which returns you to the same place" (Cilliers, 2006:107). As such, whilst one must acknowledge the complexity of 'thinking like a mountain', this thesis also emphasises the opportunity that this perspective offers in an understanding of socioecological contexts.

In order to address the complex nature of our studies, we will have to acknowledge that, whilst we once reigned as 'rightful' kings and queens of the world, the unearthing of our 
subjectivity has revealed that we are just another species trying to survive a much larger story. Nevertheless, we are an exceptional species, and from the 'mountain mind' paradigm, we can reason with these limits in mind. Since our approach to the beautifully messy would acknowledge the inherent complexity of this approach, we can be encouraged in acknowledging that 'thinking like mountain' is itself beautifully messy.

\section{3: Thinking like a Mountain in the Context of Food Systems}

By acknowledging complexity, scientific thinking and academic inquiry positions itself more suitably to address the issues of sustainability transitions, and more importantly, appropriately approach the ethical complexity of these drastic times. However, it is necessary to reflect on the paradigmatic implications of 'thinking like a mountain', so as to appreciate its revolutionary appeal. As such, the context of food systems has been provided as a space in which we can engage more critically with what it means to account for complexity.

When we are 'thinking like a mountain', it is acknowledged that the food system is an open and complex system. As such, the systemic nature of its sustainability issues would mean that they "cannot be understood in isolation ... [since] that they are interconnected, and interdependent" (Capra, 1996:3). An appropriate approach would, therefore, have to acknowledge that there are various contextually-defined components involved - some not even directly involved in the system - whose interactions with other components, and the system as a whole, are more important than the components themselves. Since it is this contextualised interactivity that constitutes the dynamic organisation of the system, sustaining the food system would, therefore, mean studying these interactions and sustaining those relationships that complement the vitality of the food system.

Of course, to an extent, the insight of the 'production paradigm' still has its place in a complex approach to understanding the food system. However, in studying the food system as a complex system, the openness thereof must be acknowledged, and similarly acknowledge that, amongst others, "the environmental system and the health/disease system are in dynamic interaction with the food system at various levels" (Drimie \& McLachlan, 2013:217). As such, any study that is aimed at researching what relationships maintain the integrity of the food system would have to include "the entire food value chain, from agricultural input markets, through food production, processing, distribution, retail, consumption and waste handling, as well as regulatory functions and support services" (Drimie \& McLachlan, 2013:217). Scientists and researchers should now be able to embrace 
the idea that the sustainability of the food system is about much more than production, but also, amongst others, about the "stewardship of the land, preservation of the resource base, the health of farm workers, the preservation of the small biota that are rich in biodiversity and are interspersed with fields, [and] the value of rural communities" (Chrispeels \& Mandoli, 2003:6).

Nevertheless, given that the complexity of the food system is irreducible, we must remember that we will never be able to account for the full systemic nature thereof. For example, the 'production paradigm' offers some relevant knowledge to our academic inquiry of the food system, but its understanding thereof is, of course, limited by its own disciplinary context. It is, therefore, suggested that the necessary strategies of reductionism in our own academic inquiries are countered with a modest openness towards other disciplines, thereby "actively embracing plural, participatory, and interrelated strategies for sustainability" (Audouin et al., 2013). This would support the notion that, in light of the failings of the 'production paradigm', "new collaborative relationships and networks are needed to move the food security agenda forward" (McLachlan \& Hamann, 2011:429).

Indeed, even the controversial players of genetic engineering - like that of Monsanto - will have a role in addressing food security. Given that the academic playing fields are levelled, the influence of such corporations cannot be denied, since "science and technology will have an increasingly important role to play in mitigating the negative effects of the forces of change on the world food system and their impacts on the poorest and hungry people" (von Braun, 2009:13). When entering an academic dialogue, academic inquiries should, therefore, begin by being explicit about the framing strategies of its research, as well as openly identifying the scientific context from which it approaches a food system issue like food security. As such, other disciplines, which are also expected to adopt this approach of openness and modesty, will be able to shed a different light on this respective issue, and as a result, a deeper understanding of the food system context is revealed. This will result in the fruitful potentiality of "in-depth disciplinary research on defined issues with integrated research programmes that span disciplines and sectors, [and] engage stakeholders" (Drimie \& McLachlan, 2013:217)

However, in acknowledging the complexity of the food system and the limited access to knowledge thereof, academia will also have to acknowledge that this context is in permanent flux, which risks this contextually-defined knowledge being rendered obsolete. As such, 
'thinking like a mountain' demands academic discourse to continue with every change of the food system context - we need a "permanent potentiality for the evolution of knowledge" (Max-Neef, 2005:13). Indeed, an appreciation of complexity tells us that "both systems and systems thinking continually evolve" (Blewitt, 2008:43). So, as well as emphasising the value that a multidisciplinary approach or an interdisciplinary approach can offer, a dedicated effort to realising sustainable food systems must go a step further. Therefore, when we are 'thinking like a mountain', we need to acknowledge the ongoing commitment to academic discourse that is inherent in the approach of transdisciplinarity, which defines itself as "both a tool and a project" (Max-Neef, 2005:15). As such, this thesis argues that this academic approach to food system challenges can be regarded as a virtuous circle, since "a knowledge feedback loop is critical to the sustainability of complex adaptive systems" (Lotrecchiano, 2010:59). This has led Drimie and McLachlan (2013:219) to explicitly pronounce that "food security is a transdisciplinary challenge and requires transdisciplinary responses".

It is fitting that, in order to address the challenges of a complex system like the food system, we match it with the complexity of the transdisciplinary approach. However, this is no small task. Indeed, the transdisciplinary approach pays "particular attention to joint learning" (Drimie \& McLachlan, 2013:217). After all, one of the most fundamental messages about sustainability transitions is that, in the Marxist spirit, "if you want to change the world in a constructive direction, you better try to understand it first ... [which] means learning" (Chomsky, 2012:44). There have been mistakes made due to 'thinking like a machine', but now academia must learn from those mistakes. Indeed, progress comes from reworking earlier errors. In a community where "information and ideas flow freely through the entire network ... [then] the diversity of interpretations and learning styles - even the diversity of mistakes - will enrich the community" (Capra, 1996:303-304). However, to commit to this learning process is also not simple, since "assuming that high levels of interaction between stakeholders in any given situation will lead to social learning is simplistic, and a deeper understanding of the context, power dynamics, and values that influence the ability of people and organizations ... is necessary" (Reed et al., 2010).

Nevertheless, as an alternative approach to sustainability transitions, 'thinking like a mountain' presents a more appropriate way of scientific thinking about food systems issues, and thus offers a suitable position from which academic inquiry can address these complex issues. It challenges scientists and researchers to think critically about certain concepts in a new manner, like what it means to have knowledge about the food systems context, or how 
'food' is understood in different contexts, and the interconnected relationship of production and consumption, which would, for example, encourage a learning process of appropriately balancing localised farming practices with large-scale industrialised agriculture.

Whilst the 'mountain mind' is aware of its normativity, and as such, ethical in its openness and critical self-reflection, it is still necessary to ask how this paradigm of thought would address an explicitly ethical experience. Such a continued critical reflection would provide a deeper understanding of what it means to account for complexity, since we cannot discuss philosophy without discussing ethics. However, it is also clearly imperative to address this in the context of sustainability transitions, especially given the ethical complexity of a complex food system, in which difficult moral choices will have to be made.

\section{4: Chapter Summary}

This chapter presented the beginning of the philosophical exploration on how to think about ethics in sustainability transitions - from the perspective of complexity. By doing so, academia's approach to ethics in the context of sustainability transitions can now be appropriately positioned.

The first section introduced the imagery that demonstrates a way of thinking that, in contrast to 'thinking like a machine', attempts to account for complexity, namely 'thinking like a mountain'. From this introduction, the next three sub-sections presented the principles of this complex way of thinking, and the implications thereof.

Firstly, the revolutionary ontology and epistemology of complex thought was introduced, through the imagery of 'a renaissance in reductionism and onwards'. Secondly, through the imagery of 'binding binaries and beyond', it was investigated how this way of thinking embraces and depends upon the contingency of difference and the views of others. Thirdly, through the imagery of 'the mountain mind in modesty', this sub-section introduced the inherently ethical element of this paradigm, and therefore, complemented the implications of the previous two sub-sections by commenting on the necessary attitude of modesty.

The last section of this chapter provided a contextual reflection of this paradigm of thought with regard to food systems, and focused on how this complex way of thinking will affect academia's approach and interest in realising sustainable food systems. 


\section{Chapter Five: An Emerging Ethics - Imagining Complex Ethics}

\section{1: Chapter Overview}

In short, this chapter will follow on from the insight provided by the previous chapter, so as to offer an appropriate way of thinking about ethics in sustainability transitions - one which accounts for complexity. As a critical philosophical exploration, this chapter will demonstrate how the very way of thinking from a complexity perspective is inseparable from its understanding of ethics, and as such, will be suitably positioned to address the ethical complexity of the ever-contingent realities of socioecological interactions.

The first section will introduce the imagery that demonstrates how this demanding understanding of ethics addresses complexity, namely 'practising provisionality'. Following this introduction, the next three sub-sections unpack the fundamentals of a complex approach to ethics, and the implications thereof.

Firstly, through the imagery of 'a renaissance in responsibility', the pressure and importance of addressing ethical complexity is presented, as well as the demanding strategy to do so. Secondly, through the imagery of 'collaborative conversations and to be continued', is the exploration of how a complex understanding of ethics relishes and revels in the contingency of difference and contrasting positions in an ethical context. Thirdly, through the imagery of 'an emerging ethics in earnest', this sub-section highlights the continuous commitment that is needed in 'practising provisionality', and therefore, complements the implications of the previous two sub-sections by commenting on how a complex ethics must be regarded as a process of social learning.

The last section of this chapter provides a contextual reflection on a complex approach to understanding ethics with regard to food systems, and concentrates on how this will affect academic interest in realising sustainable food systems.

\section{2: Practising Provisionality}

The extent of revolutionary thinking that the 'mountain mind' paradigm has introduced is most notable in our conceptualisation of ethics. From the perspective of complexity, we can no longer be content with the processed and packaged product of 'manufacturing morality', "since complexity implies a serious engagement with contingency" (Woermann, 2013:vii). 
As such, we will have to dedicate 'how we ought to live' in a way that will satisfy a constant and critical engagement with this contingency; by 'practising provisionality'.

The sensitivity of complex interactions, across social and ecological systems, has meant that ethical actions can have consequences that fall outside of an ethical context, and similarly, that actions that are not considered to be part of an ethical context can have ethical consequences. The implication of this, as emphasised in this thesis, is that the question of what it is to be ethical can no longer equate to a simple calculation, and as such, our understanding of what it is to be ethical becomes exponentially complex. So, as the tight grip that the 'machine mind' has held on moral philosophy slowly loosens, "the simplistic idea of a just society, founded on a scientific ideology and the creation of the new man, is unravelling under the pull of a multidimensional complexity" (Nicolescu, 2002:37).

However, whilst this unravelling has shed some light onto an extending ethical context, the paradox is that we will never be able to consider the 'true' extent of this context, and as a result, we will never know the 'true' meaning of what it is to be ethical. As said earlier in this thesis, an appreciation of complexity reveals to us that there is an inherently normative element in our slow and soft reductionism of complexity, but ironically, however, is that this also applies to the study of ethics. As such, "the logic which informs the ethics of complexity commits us to accepting the complexity of ethics" (Woermann \& Cilliers, 2012:404). This thesis, therefore, emphasises that the moral dilemma is something that emerges at each complex interaction. In other words, every experience of complexity is an 'ethical experience of complexity'. This means that we will have to reconceptualise our understanding of this 'emerging ethics' "as something that constitutes both our knowledge and us, rather than as a normative system that dictates right action” (Woermann \& Cilliers, 2012:404).

Of course, this revelation reveals "the fundamental problem of complexity which is epistemological, cognitive, paradigmatic" (Morin, 2007:10). However, if academia dedicates itself to honestly reflect on this realisation - by participating in the complex system of ethics - then our inquiries will not only be in the position to appropriately understand the complexity of our studies, but also to address ethics more appropriately. It is, therefore, in addressing the drama and possibilities of the 'ethical experience of complexity' - by 'practising provisionality' - that we are able to not only readjust our moral compass, but to also change the way we navigate. 


\subsection{1: Towards a Renaissance in Responsibility and Onwards}

When the seriousness of acknowledging our 'ethical experience of complexity' is understood, we become aware of the extent to which all previous moral expectations are exceeded. The magnitude of reflection and courage of decision-making that is demonstrated in complex ethical reasoning is not just expressive of an extended moral consideration, but also an exceptionally demanding moral responsibility. The gravity of addressing our ethical understanding of complexity is, therefore, met with the heaviness of 'practising provisionality'.

We are reminded that our position in a complex system is only validated by our relation to the system. In ethics, therefore, our effective relationship is determined by the choices we make. As such, the values that we decide upon can be understood as "emergent properties of the social system" (Cilliers, 1998:111). So, if we are serious about engaging ethically in the world, this will mean that we will have to engage with a system of ethics - we must make choices - otherwise "without the energy provided by engaging with the system, it would probably wither away" (Cilliers, 2000a:28). However, the complexity of ethics reveals to us that there is no way to judge whether the decisions we make are 'right' or 'wrong', since there is no a priori grounds on which to base our moral choices. Nevertheless, this does not mean that we cannot say anything about our moral responsibility. Quite the opposite, in fact, since an acknowledgment of complexity "sets us free, not to do as we like, but to behave ethically" (Cilliers, 1998:138).

Whilst these decisions may be made "in the dark" (Cilliers, 2000a:29), we are not blind. Morality is, "at the very least, the effort to guide one's conduct by reason - that is, to do what there are the best reasons for doing" (Rachels \& Rachels, 2007:14). The impetus of ethics is, after all, to address how we think we ought to live. Yet, what we think is 'best' is, of course, always framed by our subjective surroundings, and therefore, a reduction of the ethical complexity with which we are faced. We will never be able to account for all the facts and figures, contextual factors and feelings, and as such, we will always fail in our "attempt to do homage to non-existence" (Woermann \& Cilliers, 2012:410). This brings us back to the complexity of ethics, and there is no escaping this. However, rather than giving up, we are asked to give more, since our responsibility is not just to the decision, but to "the consequences of the judgement - which are never fully predictable" (Cilliers, 2004:24). 
In this light, Cilliers (2004:24) invites us to "do the best we can each time we have to make an ethical choice", since the question of 'how we ought to live' is a question that we have to ask at every 'ethical experience of complexity'. This introduces a strategy to guide our morality called 'the provisional imperative' (Preiser \& Cilliers, 2010), which necessitates explicit and vigorous moral reasoning at every 'ethical experience of complexity', along with the understanding that each decision is subject to revision. Every moment is a moment that urges us to question the appropriateness of the values that we apply to a context. As such, this strategy is able to somewhat satisfy the ongoing demands of an 'emerging ethics', which allows us as morally engaged citizens to remain open to the complexity of ethics, whilst at the same time, acknowledging the necessity of reducing that complexity through our ethical decision-making (Woermann, 2013). Like a self-critical reflection, it requires a constant and recursive rationality - it is a practice, and so, it must be "perceived as a process" (Cilliers, 2004:19). So, whilst justice will not come as a consequence of our ethical decisions, we will have to accept that it too comes as an emergent property only in "the moment of the decision" (Woermann, 2013:115). Nevertheless, once the decision is made, justice will have, of course, been thwarted, and it is expected that the process of 'practising provisionality' begins again.

The commitment required to 'practising provisionality' is dreadfully demanding, and the pressure of always and necessarily engaging with our 'ethical experience of complexity' is like no other expectation of moral responsibility. Of course, we will never be able to account for the entire collection of our normativity, and at this point, we should be "sensitive to the facts about human nature" (Rachels \& Rachels, 2007:192). However, the system of ethics is a system with a history, so it would be unreasonable and irresponsible to go about 'practising provisionality' without considering “our moral tradition" (Woermann, 2013:120). We can, as a result, be mildly comforted by the assurance that, whilst moral facts cheat the game of ethical strategising, we can play around with moral rules. The complexity of ethics is, after all, "the outcome of freedom and structure" (Woermann, 2013:112). We must remember that the earlier critique of modernist ethics was not directed at moral rules, but rather directed at our strict adherence to their existence. So, we must acknowledge that this position gives us the right to accept the formalisation of ethical action, but at the same time, the responsibility of 'practising provisionality' requires us "to remotivate the legitimacy of the rule each time we use it" (Cilliers, 1998:139-140). Of course, it is not the purpose of this paper to provide these principles - this would require contextual reasoning - rather, the purpose is just to emphasise how we should go about practising such principles; provisionally. 
In the context of sustainability transitions, our understanding of this complex ethical reasoning is immeasurably important, since "a crux of success of failure as a society is to know which core values to hold on to, and which to discard and replace with new values" (Diamond, 2005:433). These decisions, however, will have already been informed by a history of smaller and implicit choices. These 'big' decisions must, therefore, be acknowledged to be part of a process that has already begun - we are always making 'big' decisions. So, it is imperative that to understand sustainability transitions as not just having an ethical element, but as something identifiably ethical, and therefore, that we encourage an entire culture of 'practising provisionality'. As such, the decision-making process, at all levels and in all spheres, must remain explicit and transparent, so as to keep our commitment to 'practising provisionality' from straying out-of-practice. Indeed, as stated by Max-Neef (2005:9), "if ethical principles and values that should conform a society orientated towards the common good, are not made explicit, no policies coherent with the challenge can be successfully designed".

We must accept that the luxury of our critical position has been balanced out by "the loneliness of moral choice" (Bauman, 1992:xxii). In this regard, the unending responsibility of 'practising provisionality' is not easy, and indeed, overwhelming. Nevertheless, this is the nature of ethics and what keeps it relevant - the dilemma of ethics is ethics itself! In Rodin's The Thinker, this tension is timelessly portrayed, representing the eternal strife and struggle to understand our dilemmas, as both contexts and our knowledge of contexts change. We must, therefore, accept and embrace our engagement with ethical complexity.

\subsection{2: Towards Collaborative Conversations and to be Continued}

The demands and pressure that we face in 'practising provisionality' may be cripplingly consuming, especially for those of who have remained passive. However, we must realise that this is a sensation that we all share, since we are all faced with the same expectations of moral reasoning. Even though our choices are individual, ethics is, after all, a social activity. It makes sense, therefore, that we should nurture our understanding thereof through "trusting relations and through an active recognition of, and engagement with, difference" (Woermann $\&$ Cilliers, 2012:404-405). So, in our engagements with moral dilemmas, we must celebrate the opportunity to participate in this complex system.

Although ethics will never be easy, we should welcome any offer that makes its difficulty more tolerable. Indeed, when we acknowledge that we are not completely alone on our 
ethical journeys, we are reminded of why we engage with the questions of 'how we ought to live'. Human beings are social creatures, and we delight in company. Indeed, when we are faced with making difficult decisions in our appeal to 'do justice' and to 'do good', "we find ourselves impelled to act in certain ways as a result of deliberation, as a result of thinking about our behaviour and its consequences" (Rachels \& Rachels, 2007:193). However, more than a convenience, this is actually a rational strategy of ethical reasoning - as long as we remain in collaborative conversations, not conflicting cut-offs. After all, if we want our culture to be an ethical culture, "we need a revolution of human relationships" (Krznaric, 2008:18). So, we are asked to commit to discourse and dialogue as "central to guiding our way and to defining the most ethical path possible" (Chrispeels \& Mandoli, 2003:8).

Therefore, rather than seeing the diverse ethical theories that have emerged throughout the history of rationality as a useless space of wasted energy, we should make the most of the fantastic opportunity to be relieved of the weight of moral choice, and revel in all that is offered. Indeed, if we believe that a system of ethics is something worth attending to, "resilience necessitates the preservation of diversity" (Kagan, 2010:1095) - the variety within the system will ensure a rich flow of information and energy, which will keep it robust and relevant. After all, amongst all the narrow-mindedness, the history of modernist ethical theories is, of course, filled with interesting and respectable insights into 'how we ought to live'. Arguably, if we were left without these theories and critiques, there would be no present of future case for ethical action - the incentive for this study's argument would have not existed, let alone the argument itself. As with the foundation of established principles and positions, the richness of ethical interpretations provides us with a somewhat pro-active approach to complex ethical reasoning. From this perspective, we can understand how 'practising provisionality' is both a self-directed strategy, and a socially-engaging strategy.

What this means is that we should open up to those ethical position and values from which we have been distanced when 'thinking like a machine'. This would entail welcoming back the subordinated theories of care and compassion from feminist literature, as well as accepting the insights of indigenous and localised understandings of 'what is right and what is wrong'. However, this openness also means that we cannot now turn our backs on the dominant masculine theories of duty. Indeed, part of our moral responsibility can be understood, to an extent, as the duty to care. As feminist-ethicist Baier (1994:4) has said in light of this understanding, "women theorists will need to connect their ethics of love with what has been the men theorists' pre-occupation, namely, obligation". We are, therefore, 
encouraged to "make room for myth, feeling, love, and regret, and consider them rationally" (Morin \& Kern, 1999:129). Yet, in the expectation of openness, 'practising provisionality' still expects that we make choices and draw the contextual line - it still "has to inspire moral action of some form" (Krznaric, 2008:11). In other words, we must keep our blinds up, but not keep our windows wide open. Given this acceptance, we can appreciate the practice of provisionality to also be understood as a commitment to act on informed empathy.

It is, nevertheless, this openness to otherness that will be critically influential in guiding socioecological systems along our sustainability transitions. After all, with regard to embracing the values of care and compassion, it is quite evident that the atrocities that we have inflicted on others, on the Earth, and on ourselves require "a response from the heart" (Hawken, 2007:188). Harvard biologist Gould (1993:40), who has clearly stepped outside his discipline's boundaries, says that "we cannot win this battle to save species and environments without forging an emotional bond between ourselves and nature as well - for we will not fight to save what we do not love". In this light, Kagan (2010:1098) offers the notion of an 'open ethics' as a framework for allowing such an appropriate ethical culture to grow, which would "require that the individual human being be always reflexive about his or her own perspectives on reality and about the contingencies in which he or she is embedded". Therefore, in understanding the ethical complexity of sustainability transitions, the "freedom to appeal to a variety of value systems may ultimately prove the greatest strength of the movement" (Norton, 1991:12).

Yet, we must again remember that with the liberty of ethical reflection also comes the necessity of ethical decision-making, albeit provisional. The balancing act of openness and assertiveness will remain a massive obstacle, given the sensitivity of sustainability issues. This will, of course, be expected, especially when there are a multitude of stakeholders that are directly involved - for example, between localised value systems and institutional value systems. In such cases, the openness of ethical debate may be a hindrance. However, any inflexibility towards ethical dialogue must be acknowledged as a side-effect of the "machine mind' sickness - it might not be something we can cure, but it is something that we can remedy. It is, in anyway, our moral responsibility to engage in these discussions, because, as Morin has said, "the knowledge of complexity demands a politics of civilization" (Nicolescu, 2002:37). 
Of course, the enlarging of our moral consideration, not only with regard to socioecological systems, but also with regard to how we allow our ethical reasoning to be guided by the variety of values, does not provide us with an escape route to the difficulty of moral choice. We are still left with the demands and pressures of our moral responsibility. However, our collective participation in the complex system of ethics does make the personal journey of 'how we ought to live' more tolerable. This is important encouragement when 'practising provisionality', and may bring back a sense of structure to our societal behaviour.

\subsection{3: Towards an Emerging Ethics in Earnest}

As we navigate our way through sustainability transitions, we will have to commit to the difficult demands and ever-present pressures of addressing an 'emerging ethics'. It is our moral responsibility, but we must also appreciate that it is also an opportunity to approach our complex issues more appropriately. So, whilst we might be fooled into thinking that 'practising provisionality' will numb our creativity in approaching the beautifully messy, we need to reflect on the extent to which 'practising provisionality' is able to add advantage to our efforts of addressing complexity.

A complex ethics makes a seemingly impossible request. It may seem that we are destined to fail, since "it is only to be expected that sometimes we try to avoid listening to its demands" (Rachels \& Rachels, 2007:47) - only to be inclined to start again. As such, the practice of provisionality and its recursive rationality can naively be interpreted as a recurring dream of order - a dead-end job. Indeed, it is our own choice to adopt this perspective or not, but it risks us giving up on reason and giving in to the impulsiveness of pure pragmatism, which is an inappropriate approach to 'how we ought to live', especially in sustainability transitions. Addressing complexity was never going to be easy, so we must always be aware of whether we ignorantly choose the easy way out over our moral responsibility. In response to this, Degenaar (1993:56) says that "only hope as a creative expectation will suffice". Zinn (2002:208) supports this message, reminding us that "to be hopeful in bad times is not just foolishly romantic ... [but] based on the fact that human history is a history not only of cruelty, but also of compassion, sacrifice, courage, kindness".

In addressing complexity, "the importance of context and history means that there is no substitute for experience" (Cilliers, 2000b:12). The reason for hope is, therefore, that 'practising provisionality' not only underlines that our ethical decisions are provisional and require constant revision, but also that it is a practice; and like when we practice manners, we 
rely on experience. In light of this, 'practising provisionality' is a virtuous cycle, rather than a vicious cycle. It is both a necessary process of ethical decision-making, as well as an opportunity to exercise our ethical reasoning that informs that process. Of course, the ethical complexity of everything will not mean that practice makes perfect, but philosophy is "the art of reflection" (Cilliers, 2006:111), and as any artist will tell us, practice makes progress. So, whilst we must appreciate that "in reasoning about what to do, we can be consistent or inconsistent" (Rachels \& Rachels, 2007:193), we should also be reassured that we have the potential to improve upon that consistency. Life is one long 'learning curve of complexity', and since we are curious and ambitious creatures, we are on a continuous quest to understand the world and how we relate to it. As such, our history of participation with the complex system of ethics, and our "artful practice of life" (Kagan, 2010:1100), will inform our understanding of ethics, and therefore, our practice of provisionality.

Indeed an 'open ethics' is both an "ethics of diversity stewardship and [an] ethics of learning capabilities" (Kagan, 2010:1098). So, if we are open to the possibility of potential - that we could always reason through our moral dilemmas more appropriately - then it motivates us that we should always look to engage in an 'emerging ethics' more appropriately. Interestingly, this also applies for the skill of critical self-reflection, since both this skill "and the provisional imperative place us under a moral obligation to stay open to the future and to the to-come, whilst simultaneously compelling us to respond to the urgency of the situation by taking in a position and assuming action" (Woermann, 2013:77). In fact, we are able to go so far as to say that, by 'practising provisionality', it is not only our complex ethical reasoning that we are working on, but also this skill of our modest rationality. As such, in our appreciation that ethics and our other ontological and epistemological questions are inextricably linked, the practice of provisionality allows us to reconnect these modernist separations, and reunite the family of philosophy. The hope that is inherent in the practice of provisionality, therefore, creates "a moral space in which the notion of a sustainable future may be articulated in a manner that may help to transform present society, its structures and processes" (Hattingh, 2012:18).

Again, we must once again be reminded that we are not alone in our learning curve of complexity. Neither we nor our knowledge can be excluded from our socioecological contexts, and so, our understanding of the world progresses as "a cerebral translation starting from data of the external world and a mental reconstruction, starting from certain organizing potentialities of the spirit" (Morin, 2007:21). In this sense, we need not draw divisions 
between individual and social learning, since this "ignores the important insight that human behaviour is both individually determined and socially embedded" (Henry, 2009:135). So, with ethics being a social activity that is energised by individual actions, we can understand the process of 'practising provisionality' to not just be an individual learning process, but also a social learning process. Indeed, whilst the concept of social learning is not uncommon, it has recently seen a surge in its use "to teach citizenship" (Reed et al., 2010). As such, it is not only our own ethical strategising that we are working on, but by having a kind of creative feedback loop, the process of 'practising provisionality' also allows people to "learn from each other in ways that can benefit wider social-ecological systems" (Reed et al., 2010). So, as with the values we choose, both this process of social learning and the benefits thereof can be understood as emergent properties of a complex system of ethics.

From this perspective, it is argued that, at every 'ethical experience of complexity', the reciprocal learning process of 'practising provisionality' can inform "some combination of virtues, motives, and methods of decision making that is best for me, given my circumstances, personality, and talents" (Rachels \& Rachels, 2007:199). However, as with any art, this is talent that we need to hone. Wisdom takes time. Yet, we need look no further than Nature for inspiration. Or as Hawken (2007:189) puts it, "all people and institutions, including commerce, governments, schools, churches, and cities, need to learn from life". After all, it has been here for a few billion years. Indeed, this is what Leopold (1991) had in mind, when he first suggested we be 'thinking like a mountain'. He saw "the mountain 'thought' in terms of ecological and geological time: the time it took to evolve plants and animals and behaviour patterns appropriate to the conditions of the mountain slopes" (Hattingh, 1999:72). Therefore, as much as we need to be 'thinking like a mountain', we also need to be 'thinking like a student' - we need to be 'learning like a mountain'.

This may be reminiscent of virtue ethics. There is, of course, priceless value in the teachings of Plato, Socrates, Aristotle and other thinkers, both ancient and contemporary, who argue for virtue ethics. Virtue ethics argue for a collection of character traits that would be "manifested in habitual action" (Rachels \& Rachels, 2007:175), in order to make you a good person. Whilst this may represent something similar to 'practising provisionality', this thesis is not prepared to label a 'correct' method and set ethical theories, and is open to any evolution of experimentation that is practised by this way of thinking - be it based on virtues or not. The purpose of this is to address what it means to engage in a complex system of ethics. 
When we understand ethics as a complex system, we play an 'infinite game', in which 'the object of the game is to keep playing" (Hawken, 2007:187). However, we are not hitting tennis balls against a wall by ourselves, but playing with a partner, knocking the balls back and forth over the net. So, more than just playing for the sake of playing, our continual and collective participation in this 'infinite game' will mean that we will learn more about the game, the context of the game, how to appropriately play the game, and as such, more about ourselves. For that reason, an honest approach to an 'emerging ethics' will provide us with the ongoing experience to appropriately play the other complex games of life.

\section{3: Practising Provisionality in the Context of Food Systems}

Our acknowledgment of ethical complexity places a massive amount of expectation on us as individuals. However, it is in assuming this moral responsibility that we are in an appropriate position to address the ethical issues and moral dilemmas that we will encounter in sustainability transitions. Nevertheless, the intricate orientation of the 'mountain mind' is something that deserves further elaboration. As such, by contextualising this understanding of ethics in food systems, we are offered the necessary space from which we can critically reflect on these expectations, and the extent of our moral responsibility.

When we are 'practising provisionality' in food systems, we acknowledge the ethical complexity of working towards providing food security. Our moral choices will be characterised by choosing one value over another, with no a priori substantiation, and with unpredictable consequences, especially in this context, since "social action and ecological effects are tightly linked" (Drimie \& McLachlan, 2013:219). As such, the moral dilemmas contextualised by the food system require a continuous ethical reasoning, known as the 'provisional imperative' (Preiser \& Cilliers, 2010). This is something to be welcomed, as "it makes sense to complement a renewed commitment to the scientific and technical dilemmas of food security with a commitment to creating spaces for dialogue and action on food and its role in our national, professional and personal lives" (McLachlan \& Hamann, 2011:430).

Of course, the simplified utilitarian doctrine of the 'production paradigm' does not account for socioecological complexity, but we must not be so quick to write-off its arguments. Indeed, it is not that its values are 'wrong', but rather that 'practising provisionality' emphasises the complexity of assuming any value. Whether we choose to follow the morality of the 'production paradigm' is our individual choice, but it is a choice we have to make at every 'ethical experience of complexity' - we cannot rely on any 'moral high-ground' when 
we engage in responsible ethical decision-making. From the perspective of an 'emerging ethics', the contingency of our ethical context means that "each situation calls for fresh judgement" (Woermann, 2013:161). The food system is an ever-changing context with many role-players and many interactions with other systems - our ethical context extend throughout socioecological systems. So, we must appreciate that the values we hold dear might not apply at certain times. This is especially relevant when we consider the uncertainty that typifies sustainability transitions.

Indeed, in understanding the complexity of ethics, we highlight "the important role that context and contingency play in shaping and informing our ethical sensibilities" (Woermann, 2013:160-161). As such, whether we are a producer or a consumer, a politician or a fruitpicker, our socioecological interactions with the food system all need to go through a necessary process of ethical reasoning, although this will still represent a necessary exclusive moral consideration. As such, this ethical reasoning will have to begin again, with every experience that relates either directly or indirectly with the food system. This is the nature of 'practising provisionality'. This reasoning is further thickened by the fact that, "if the moral community is not limited to people in one place, neither is it limited to people at any one time" (Rachels \& Rachels, 2007:200). For example, we will have to consider the context and values of those that would live in time of extreme global warming. Of course, we would not know the exact circumstances, but it is still our moral responsibility to consider this. In this light, we will have to approach our understanding of inter-generational and intra-generational justice, with regard to the food system, as a slow and reflective journey, not a 'quick fix' kind of thing.

As such, when reasoning through the difficulties of making moral choices in the changing context of the food system, we must take advantage of the potential insight that exists in ethical discourse. Ideally, this would accommodate all those involved in our food system, "either directly as farmers, or indirectly as government regulators, extension agents, researchers, CEOs, industrial workers, lawmakers, technology developers, consumers, or protestors" (Chrispeels \& Mandoli, 2003:4). Indeed, by keeping the ethical debate alive, we keep a system of ethics alive and relevant in sustainability transitions. However, the necessity of reductionism does not give us the luxury to hear everyone's moral opinion. And so, deliberation on moral dilemmas would stress the importance of being explicit in what has been excluded from moral consideration. This ensures that our ethical reasoning remains refined, as "good decision-making procedure requires that implicit value judgements be made 
explicit, so that more of the actual decision-making process becomes visible" (Clayton \& Radcliffe, 1996:11). Furthermore, this understanding of the foundation of moral judgements in this context "ought to lead to more confident judgements" (Zimdahl, 2002:44).

Of course, there will always be conflicts and disagreements in working towards realising a sustainable food system. Food is, after all, a sensitive subject; it is "a matter of culture, religion, status and social discourse" (McLachlan \& Hamann, 2011:429). Nevertheless, this should be something that is used to critically reflect and continuously question the values we hold dear. Those involved in the academic inquiry of food systems "must accept the burden of beginning the difficult task of doing a discriminating cultural and moral analysis of agriculture and its results" (Zimdahl, 2002:51). In any case, this principle of flexibility inherent in 'practising provisionality' would suggest "a corresponding strategy of conflict resolution" (Capra, 1996:303). We must, therefore, let the conflicts and disagreements carry on and nurture each other - we must not let them fight, but we must let them play. It helps to acknowledge that such hindrances are typical of a blossoming conceptualisation of ethics, in that it will be "seldom established in a smooth and orderly fashion ... [and] similar to a political revolution, a variety of different and often incompatible outlines, coupled with a wide range of protopractices and even social experiments, are tried out" (Hattingh, 1999:80).

This brings us to the understanding of 'practising provisionality' as a process of social learning. We must accept that, in our ethical journey of realising the sustainability of food systems, the arguments about which systemic relationships to sustain will vary, "and much of the skill of moral thinking consists in discerning the difference" (Rachels \& Rachels, 2007:12). It is, therefore, not only important that we engage in 'practising provisionality' so as to account for ethical complexity, but also to constantly practise this skill of complex ethical reasoning through discourse. Indeed, this is the nature of learning in a social system, in that it expands our "understanding of human-environment interactions, and the problems at stake" (Cundill \& Rodela, 2012:11). So, when we commit to 'practising provisionality' in the context of food systems, "different perspectives ... come together in a learning process whereby, in the course of the interaction, implicit knowledge is made explicit, and new knowledge is construed, shared and tested" (Drimie \& McLachlan, 2013:219). This starts all over again at each moral choice, and at every process of complex reasoning, our contextual sensibilities become ever-more heightened, like muscle memory. This will, of course, be a long arduous journey of social discovery. However, those committed to realising sustainable food systems must constantly remind themselves to not only practise this complex ethical 
reasoning, but also that whilst "we live in a post-industrial, information-age society ... we do not, and no one ever will, live in a post-agricultural society" (Zimdahl, 2002:52).

The extent of moral responsibility that awaits us, as individuals, is as complex as our understanding of ethics. However, by reflecting on this realisation in the context of realising sustainable food systems, we can now begin to conceptualise this expectation, and practice the necessary strategy of provisionality as a process of social learning. Furthermore, we can be encouraged that, through constant dedication, practice will make progress, and as such, we will slowly learn to address sustainability transitions in a more appropriate and ethical way.

\section{4: Chapter Summary}

This chapter followed on from the insight provided by the previous chapter, in providing an appropriate way of thinking about ethics in sustainability transitions - one which accounts for complexity. It has been demonstrated how the very way of thinking from a complexity perspective is inseparable to its understanding of ethics, and therefore, how such an approach is suitably positioned in addressing the ethical complexity of the ever-contingent realities of socioecological interactions.

The first section introduced the imagery that demonstrates how this demanding understanding of ethics addresses complexity, namely 'practising provisionality'. Following this introduction, the next three sub-sections unpacked the fundamentals of a complex approach to ethics, and the implications thereof.

Firstly, through the imagery of 'a renaissance in responsibility', the pressure and importance of addressing ethical complexity was presented, as well as the demanding strategy to do so. Secondly, through the imagery of 'collaborative conversations and to be continued', it was explored how a complex understanding of ethics relishes and revels in the contingency of difference and contrasting positions in an ethical context. Thirdly, through the imagery of 'an emerging ethics in earnest', this sub-section highlighted the continuous commitment that is needed in 'practising provisionality', and therefore, complemented the implications of the previous two sub-sections by commenting on the how a complex ethics must be regarded as a process of social learning.

The last section of this chapter provided a contextual reflection on a complex approach to understanding ethics with regard to food systems, and concentrated on how this will affect academic interest in realising sustainable food systems. 


\section{Chapter 6: Conclusion}

\section{1: Closing Remarks}

This thesis has stressed the importance of acknowledging that today's polycrises are largely a result of yesterday's failure of realising the modern dream of order; "the exacerbation of rational thought, which manifests itself through the predominance of reductionism and a binary and linear logic that, among other shortcomings, separate the observer from the observed" (Max-Neef, 2005:10). Therefore, in understanding ethics in sustainability transitions, an appreciation of complexity will play a significant role in remedying the devastations that have been inflicted, and remedying the minds that have blindly engineered these devastations.

Of course, whilst it would be foolish to throw away reductionist principles completely, it is still necessary to highlight how it can manifest in ways that neglect complex contexts and claim objectivity, to disastrous effects. In this light, the resonating words of Cilliers (1998:127) declare that "liberty and justice will not come about through the imposition of universal laws ... nor will science flourish if it maintains a closed shop and speaks a private language". So, whilst the world might find itself in a time that brings doubt and uncertainty, academia must engage in this transition of thought - it is our moral responsibility. Indeed, as it has been written by Jared Diamond (2005), the relevance of understanding ethics in sustainability transitions is that society will choose whether it will collapse or flourish.

Nevertheless, in response to the excitement of Capra's earlier remark, the potentiality of complexity thinking is also an "anthropological and historical problem ... of considerably greater proportions than the Copernican revolution ... [and] never before in the history of humanity have the responsibilities of thinking weighed so crushingly on us" (Morin \& Kern, 1999:132). Scientific research must, therefore, remain in a constant state of learning, so as to appropriately adapt to the changing contexts, like that of complex food systems. At the same time, however, if we fail to re-orientate our thinking now - if we fail to acknowledge the global polycrises as issues that emerge from complex systems, and fail to practise a complex ethical reasoning - we gamble with "the kind of social and economic dislocation and collapse that a number of earlier societies have already experienced" (Clayton \& Radcliffe, 1996:4).

As such, this thesis declares that now is the time to act, to commit, and to have hope. It is, therefore, necessary that the problems of sustainability transitions are addressed "not so much 
as scientific problems for which we must find technical solutions, but rather as ideas that challenge us to think creatively and deeply about how we want to live together on this finite planet" (McLachlan \& Hamann, 2011:429). Indeed, as Woermann (2013:169) says, "now is the time to sow the seeds of new ideas, in the hope that these may take root, grow, and blossom in the cracks".

\subsection{1: Thesis Review}

As mentioned in the introduction, this thesis presented a conceptual analysis to ask what an appropriate understanding of ethics would look like, given the context of sustainability transitions, particularly with regard to realising sustainable food systems. After an in-depth literature review and critical exploration, it has been argued that the dominant paradigm of thought and its approach to ethics is inappropriate in its disregard for the contingencies of socioecological interactions. As such, the self-critical perspective of complex systems has been suggested as an appropriate way of thinking about ethics in sustainability transitions.

After a brief introduction to the thesis, the dominant way of thinking, referred to as the 'machine mind', was investigated and discussed in the second chapter. As a prolific understanding of the dynamic and unpredictable nature of our polycrises roots itself in Western academia, this thesis has, therefore, provided a critique on the 'machine mind' and its reliance on strict reductionism, and the conservative binary logic that accompanies it. This way of thinking about the world and how we relate to it is extremely unreflective, and as such, inadequate. Its avoidance of engaging with the contingencies of complex contexts is unacceptable in these times, and whilst it has produced fascinating discoveries and technologies, a continuation thereof will risk further misunderstanding of these contexts of sustainability transitions. This position is supported, thereafter, by reflecting upon this paradigm of thought's one-dimensional and narrow-minded interpretation of the issue of food security.

The third chapter saw to complement the previous chapter, and further emphasised the inadequacies of the 'machine mind'. This chapter, therefore, investigated and discussed the way in which ethics is understood from this strictly reductionist perspective. Similar to its ontological and epistemological simplifications, this way of thinking produces overly reductionist interpretation of what it means to be ethical, asking only for an obedience to moral rules, and in turn, discards the power and possibility of moral choice. Its 'engineered ethics' is ignorant of both the ever-changing story of ethical theory and of the contingencies 
of moral dilemmas. As such, it offers an unacceptable and misleading response to the question of moral responsibility in the context of sustainability transitions. To support this critique, this thesis then reflected upon this way of thinking's arrogant and unquestionable interpretation of morality with regard to realising sustainable food systems.

After the explorative critique of the traditional paradigm of thought, which dominates current academic enquiry, it was necessary that this thesis continued its critical exploration, from which a more appropriate way of thinking about ethics in sustainability transitions could be provided.

In chapter four, the paradigm of thought referred to as the 'mountain mind' was introduced. By identifying and elaborating on its fundamental principles, it was revealed that this way of thinking acknowledges not only the contingent contexts of complex systems, but also dares to approach this reality in complex way itself. The paradigmatic shift in understanding the world as organised through dynamic relationships emphasises the incompressible nature of complexity, yet the need to apply a soft and slow reductionism. Its sensitivity is further supported by a liberal binary logic and a modest engagement with its contextualised knowledge claims. As such, the 'mountain mind' way of thinking offers an appropriate alternative to the complications of strict reductionism in addressing sustainability transitions. This position is complimented, thereafter, by reflecting upon this way of thinking's cautious open approach to the issue of food security.

Following from the previous chapter, the fifth chapter of this thesis saw to explore how this complex way of thinking approaches ethics, and comment on its appropriateness. Whilst the 'mountain mind' acknowledges an implicit normativity, the way in which ethics is addressed explicitly from this perspective is similarly complex. Rather than insisting on a certain rule of ethical behaviour, this thesis revealed how a complexity perspective reasons anew through every choice of an 'emerging ethics' with informed openness and reflection. This suits the contingency of ever-changing contexts of complex systems, and the ethical complexity that is implied in each experience thereof. The extent of moral responsibility is met with hope, as this thesis comments on how this process of ethical reasoning is also a process of learning, which will comfort this developing understanding of ethics in sustainability transitions, and the trickiness of complex thought. To support the appropriateness of this complex ethics, this thesis then reflected upon the tolerance and dedication that is required of an 'emerging ethics' in realising sustainable food systems. 


\section{2: Limitations of the Research}

Admittedly, this thesis represents only a small part of an evolving resource of academic literature on sustainability transitions. Knowledge is always changing, so academia must understand the importance of showing modesty when producing knowledge. All researchers should welcome receiving feedback and response, so as to continuously explore and learn more about the subject of their study. Therefore, in order to build on the debate of complex systems and ethics, readers are invited to be constructively critical. To initiate this discussion, the limitations and laggings of this philosophical argument will now be openly discussed - to exercise a self-critical rationality.

To begin, it is important to expose the framing strategies of this study. Western literature is favoured in this thesis, and it is the source of knowledge from which the argument has emerged. However, excluding the significance of the different perspectives and types of knowledge from 'Other' disciplines and cultures has been detrimental to the robustness of this thesis' argument. Indeed, there is great progress to be made in welcoming previously separated sciences, for example Oriental and intuitive science. The argument presented in this thesis comes also from a position of youth and idealism. And given the constraints of time and funding, this academic study was structured in such a way that it missed out on the insight provided by sufficient conversation and collaboration, and was somewhat directed by the passion of these values. That being said, the freedom of the academic world is restricted by institutional and bureaucratic formalities, and perhaps such an impassioned account is needed.

There is only hope in the promise that change will come from 'practising provisionality' if the message is also heard by academic institutions. It is vital that academia is open to its own paradigm shifting. As a result, the attitude of this thesis is such that it is first necessary to introduce the message of 'practising provisionality', even if it is carried on the Western wings of youth and idealism.

In scientific inquiry, when we try and make sense of the world, our research findings will always be filtered by our subjectivity and the necessary reductionism employed when addressing complex phenomena in ever-changing contexts. This and any other research will have to acknowledge, that because of our employment of reductionism, our findings will always fall short of accounting for the anything's full information and depths of data. This thesis acknowledges its own inadequacy. As such, it is necessary that this and all research 
continues, so as to account for the dynamic system of knowledge - in an attempt to keep up with complexity.

Due to the fact that this study only provided a conceptual analysis of the traditional and an alternative paradigms of thought, and their approach to ethics, the most apparent limitations and laggings of this study may exist in the fact that it is lacking in field research. Both qualitative assessments and quantitative simplifications are excellent ways of both supporting and disagree with an argument. The reasons for the lack of field research have already been given - the constraints of time and finding meant that all resources had to be concentrated on exploring the literature's theory. Nevertheless, this arguments' message will not be accessible to all disciplines, and so it will be important to commit to a transdisciplinary environment in closing such gaps.

Given the small and concentrated literature on social learning, the thesis is also limited in its reflections of social learning as a wide concept. Subsequently, there is a possibility that readers might have expected a more direct tackling of this concept and the details of such a process in research. However, it was never the aim of the thesis to do so, as the concept of social learning was only used as a general idea about the importance of societal learning in the context of sustainability transitions.

Lastly, the argument of the thesis is such that its possible application to specific problems in food systems research is also limited. Again, it was not the intention to provide solutions to this context, but rather to provide an alternative platform from which one can think more appropriately about the challenges of food system research in general.

\section{3: Recommendations for Further Research}

The hope is that this research is the start of a project that continues to explore the ethical aspect of research in food systems. This argument in this thesis, therefore, offers a whole array of possibilities with regard to recommendations for further research. This final part of the thesis, however, will be explicit in imaging these possibilities.

There is opportunity for a lot of empirical field research of any kind that would support or challenge the argument through more accessible information, like numbers and factual data. Specifically, the notion of 'practising provisionality' would need to be tested empirically in a certain environment to see the effects of this commitment. Of course, this would be problematic to measure and decipher, although there are much more creative ways of doing 
such research than by reducing one's observations to numbers. As such, the research would more than likely represent another narrative study of journals and personal insight, but this would, nevertheless, still prove to be of value. Particular research in the transdisciplinary environment would also be welcomed.

In any case, a dedicated study on this subject could uncover the nature of a certain group's understanding of ethics as contexts changed. Personally, this kind of research would be adequately contextualised in the project team of Social Learning for Sustainable Food Systems. In a paradigm of transdisciplinarity, and over a long-term period, qualitative and quantitative empirical research of how individuals and groups understanding and approach to ethics could compare with the literature as presented in this thesis. From these findings, space for social learning and a contextualised development on this area of academia could be provided, so as to determine whether the benefits of 'practising provisionality' have any tangible evidence. Thereafter, it could be interesting to see how these findings have influenced not only individuals' understanding of ethics and their behaviour, but also how this has influenced the team's own disciplinary research on realising sustainable food systems.

There are other ways to train a way of thinking that accounts for the complex interrelations of systems, and when it comes to ethics, 'practising provisionality' could certainly be supported by these other tools. Although there has been mention of our interaction in a complex system of ethics as a game, the 'systems thinking games', as popularised by Linda Booth Sweeney and Dennis Meadows (2010) is a very creative option, which brings the fun into systems thinking. By playing these games, they allow us "to comprehend and apprehend both the working of human beings individually and in groups (with their mental models, habits and conventions), and the working of systems (with their feedback loops, interdependencies, leverage points, time delays, short-term vs. long-term loops and the structural archetypes of different systems) ... [and] also train each player's intuition and creativity" (Kagan, 2010:1097). These games could be used in concrete research to see the consequences of such games, and how this would complement 'practising provisionality'.

It is notable that more research needs to be done to give some credibility to the findings of the thesis. Also, and perhaps more importantly, is that it is necessary to continue research so that one does not get stuck in the theoretical world. Of course, a conceptual analysis has its benefits, but the nature of complex interactions is such that it academics will have to explore 
more areas of knowledge and understanding that have yet to be popularised, either personally or in one's discipline. 


\section{Bibliography}

Audouin, M., Preiser, R., Nienaber, S., Downsborough, L., Lanz, J. \& Mavengahama, S. 2013. Exploring the Implications of Critical Complexity for the Study of Social-Ecological Systems. Ecology and Society, 18(3). Available at:

http://www.ecologyandsociety.org/vol18/iss3/art12.

Baier, A. 1994. Moral Prejudices: Essays on Ethics. Massachusetts: Harvard University Press.

Battersby, J. \& McLachlan, M. 2013. Urban Food Insecurity: A Neglected Public Health Challenge. The South African Medical Journal, 103(10):716-717.

Bauman, Z. 1992. Intimations of Postmodernity. London: Routledge.

Blewitt, J. 2008. Understanding Sustainable Development. London: Earthscan.

Booth Sweeny, L. \& Meadows, D. 2010. The Systems Thinking Playbook: Exercises to Stretch and Build Learning and Systems Thinking Capabilities. Vermont: Chelsea Green.

Burns, M., Audouin, M. \& Weaver, A. 2006. Advancing Sustainability Science in South Africa. South African Journal of Science, 102(9/10):379-384.

Capra, F. 1996. The Web of Life: A New Scientific Understanding of Living Systems. New York: Anchor Books.

Capra, F. 2002. The Hidden Connections: A Science for Sustainable Living. London: HarperCollins.

Chomsky, N. 2012. Occupy. London: Penguin Books.

Chrispeels, M. \& Mandoli, D. 2003. Agricultural Ethics. Plant Physiology, 132(1):4-9.

Cilliers, P. 1998. Complexity and Postmodernism: Understanding Complex Systems. New York: Routledge.

Cilliers, P. 2000a. What Can We Learn From a Theory of Complexity? Emergence: Complexity and Organization, 2(1):23-33.

Cilliers, P. 2000b. Knowledge, Complexity and Understanding. Emergence: Complexity and Organization, 2(4):7-13. 
Cilliers, P. 2001. Boundaries, Hierarchies and Networks in Complex Systems. International Journal of Innovation Management, 5(2):135-147.

Cilliers, P. 2004. Complexity, Ethics, and Justice. Journal for Humanistics, 5(19):19-26.

Cilliers, P. 2006. On the Importance of a Certain Slowness. Emergence: Complexity and Organization, 8(3):106:113.

Clayton, A. \& Radcliffe, N. 1996. Sustainability: A Systems Approach. London: Earthscan.

Culler, J. 2008. On Deconstruction. Abingdon: Routledge.

Cundill, G. \& Rodela, R. 2012. A Review of Assertions about the Processes and Outcomes of Social Learning in Natural Resource Management. Journal of Environmental Management, 113:7-14.

Degenaar, J. 1993. Art and Culture in a Changing South Africa. South African Journal of Philosophy, 12(3):51-56.

Derrida, J. 1978. Writing and Difference. Chicago: University of Chicago Press.

Derrida, J. 1981. Positions. Translated from French by Alan Bass. Chicago: University of Chicago Press.

Diamond, J. 2005. Collapse: How Societies Choose to Fail or Succeed. London: Penguin Books.

Drimie, S. \& McLachlan, M. 2013. Food Security in South Africa - First Steps Toward a Transdisciplinary Approach. Food Security, 5(2):217-226.

Emmeche, C. 2004. At Home in a Complex World: Lessons From the Frontiers of Natural Science. In: Van Kooten Niekerk, K. \& Buhl, H. (eds). The Significance of Complexity: Approaching a Complex World through Science, Theology and the Humanities. Aldershot: Ashgate Publishing.

Gardner, G. 2003. Engaging Religion in the Quest for a Sustainable World. In: Worldwatch Institute. State of the World 2003. A Worldwatch Institute Report on Progress Toward a Sustainable Society. London: WW Norton and Company. 
Gardiner, S. 2006. A Perfect Moral Storm: Climate Change, Intergenerational Ethics and the Problem of Moral Corruption. Environmental Values, 15(3):397-413.

Gould, S. 1993. Eight Little Piggies: Reflections in Natural History. New York: WW Norton and Company.

Harding, S. 2006. Animate Earth: Science, Intuition and Gaia. Devon: Green Books.

Hattingh, J. 1999. Finding Creativity in the Diversity of Environmental Ethics. Southern African Journal of Environmental Education, 19:68-84.

Hattingh, J. 2012. Towards an 'Ethics of Hope'? In: Swilling, M., Sebitosi, B. \& Loots, R. (eds). Sustainable Stellenbosch - Opening Dialogues. Stellenbosch: SUN Press.

Hawken, P. 2007. Blessed Unrest: How the Largest Social Movement in History Is Restoring Grace, Justice, and Beauty to the World. New York: Penguin Books.

Heisenberg, W. 1958. Physics and Philosophy: The Revolution in Modern Science. Lectures delivered at University of St. Andrews, Scotland, in the Winter of 1955-56. New York: Harper and Row.

Henry, A. 2009. The Challenge of Learning for Sustainability: A Prolegomenon to Theory. Human Ecology Review, 16(2):131-140.

Heylighen, F., Cilliers, P. \& Gershenson, C. 2007. Philosophy and Complexity. In: Bogg, J. \& Geyer, R. (eds). Complexity, Science and Society. Oxford: Radcliffe Publishing. International Food Policy Research Institute. (IFPRI). 1995. A 2020 Vision for Food, Agriculture, and the Environment: the Vision, Challenge, and Recommended Action. Washington, DC: IFPRI.

Kagan, S. 2010. Cultures of Sustainability and the Aesthetics of the Pattern That Connects. Futures, 42(10):1094-1101.

Krznaric, R. 2008. You Are Therefore I Am - How Empathy Education Can Create Social Change. A report prepared for Oxfam GB. Oxford: Oxfam.

Leopold, A. 1991. A Sand County Almanac: With Essays on Conservation from Round River. New York: Ballantine Books. 
Lotrecchiano, G. 2010. Complexity Leadership in Transdisciplinary Learning Environments: A Knowledge Feedback Loop. International Journal of Transdisciplinary Research, 5(1):2963.

Lyotard, J-F. 1984. The Postmodern Condition: A Report on Knowledge. Translated from French by Bennington, G. \& Massumi, B. Minneapolis: University of Minneapolis Press. Max-Neef, M. 2005. Foundations of Transdisciplinarity. Ecological Economics, 53(1):5-16. McLachlan, M. \& Hamann, R. 2011. Theme Issue on Food Security. Development Southern Africa, 28(4):429-430.

Mebratu, D. 1998. Sustainability and Sustainable Development: Historical and Conceptual Review. Environmental Impact Assessment Review, 18(6):493-520.

Morgan, G. 2006. Images of Organization. London: Sage Publications.

Morin, E. 1992. From the Concept of System to the Paradigm of Complexity. Journal of Social Evolutionary Systems, 15(4):371-385.

Morin, E. 2007. Restricted Complexity, General complexity. In: Gershenson, C., Aerts, D. \& Edmonds, B. (eds). Worldviews, Science and Us: Philosophy and Complexity. Singapore: World Scientific.

Morin, E. \& Kern, A. 1999. Homeland Earth - A Manifesto for the New Millennium. New Jersey: Hampton Press.

Nicolescu, B. 2002. Manifesto of Transdisciplinarity. New York: State University of New York Press.

Norton, B. 1991. Toward Unity Among Environmentalists. New York: Oxford University Press.

Palmer, C. 2003. An Overview of Environmental Ethics. In: Light, A. \& Rolston, H. (eds). Environmental Ethics: An Anthology. Malden: Blackwell.

Preiser, R. \& Cilliers, P. 2010. Unpacking the Ethics of Complexity: Concluding Reflections. In: Cilliers, P. \& Preiser, R. (eds). Complexity, Difference and Identity. Dordrecht: Springer. 
Preiser, R., Cilliers, P. \& Human, O. 2013. Deconstruction and Complexity: a Critical Economy. South African Journal of Philosophy, 32(3):261-273.

Rachels, J. \& Rachels, S. 2007. The Elements of Moral Philosophy. 5th edition. New York: McGraw-Hill.

Reed, M., Evely, A., Cundill, G., Fazey, I., Glass, J., Laing, A., Newig, J., Parrish, B., Prell, C., Raymond, C. \& Stringer, L. 2010. What is Social Learning? Ecology and Society, 15(4). Available at: http://www.ecologyandsociety.org/vol15/iss4/resp1.

Robinson, C. \& Latham, J. 2013. The Goodman Affair: Monsanto Targets the Heart of Science. Independent Science News [online]. Available at:

http://independentsciencenews.org/science-media/the-goodman-affair-monsanto-targets-theheart-of-science [1 June 2013].

Scherr, S. 2000. A Downward Spiral? Research Evidence on the Relationship Between Poverty and Natural Resource Degradation. Food Policy, 25(4):479-498.

Schumacher, E. 1973. Small Is Beautiful: A Study of Economics as if People Mattered. New York: Harper and Row.

Séralini, G., Emilie, C., Mesnagea, R., Gress, S., Defargea, N., Malatesta, M., Hennequinc, D. \& Spiroux de Vendômois, J. 2012. Long term toxicity of a Roundup herbicide and a Roundup-tolerant genetically modified maize. Food and Chemical Toxicology, 50(11):42214231.

Swilling, M. 2013. Economic crisis, Long Waves and the Sustainability Transition: An African Perspective. Environmental Innovation and Societal Transitions, 6(2013):96-115.

Swilling, M. \& Annecke, E. 2012. Just Transitions: Explorations of Sustainability in an Unfair World. Cape Town: UCT Press.

Swimme, B. \& Berry, T. 1992. The Universe Story: From the Primordial Flaring Forth to the Ecozoic Era - A Celebration of the Unfolding of the Cosmos. San Francisco: HarperCollins.

Thompson, P. 1998. Agricultural Ethics: Research, Teaching and Public Policy. Ames: Iowa State University Press. 
Urry, J. 2005. The Complexity Turn. Theory, Culture and Society, 22(5):1-14.

Von Braun, J. 2009. Addressing the Food Crisis: Governance, Market Functioning, and Investment in Public Goods. Food Security, 1(1):9-15.

Warren, K. 1998. The Power and Promise of Ecological Feminism. In: VanDeVeer, D. \& Pierce, C. (eds). The Environmental Ethics and Policy Book. 2nd edition. London: Wadsworth.

Woermann, M. 2013. On the (Im)Possibility of Business Ethics: Critical Complexity, Deconstruction, and Implications for Understanding the Ethics of Business. Dordrecht: Springer.

Woermann, M. \& Cilliers, P. 2012. The Ethics of Complexity and the Complexity of Ethics. The South African Journal of Philosophy, 31(2):403-419.

Zimdahl, R. 2002. Moral Confidence in Agriculture. American Journal of Alternative Agriculture, 17(1):44-53.

Zinn, H. 2002. You Can't Be Neutral on a Moving Train: A Personal History of Our Times. Boston: Beacon Press. 